\title{
SEISMIC DESIGN OF ACCELERATION-SENSITIVE NON-STRUCTURAL ELEMENTS IN NEW ZEALAND: STATE-OF-PRACTICE AND RECOMMENDED CHANGES
}

\author{
Muhammad Rashid ${ }^{1}$, Rajesh P. Dhakal ${ }^{2}$ and Timothy J. Sullivan ${ }^{3}$
}

(Submitted November 2020; Reviewed January 2021; Accepted February 2021)

\begin{abstract}
Acceleration-sensitive non-structural elements not only constitute a significant portion of a building's component inventory, but also comprise components and systems that are indispensable to the operational continuity of essential facilities. In New Zealand, Section 08 of the seismic loadings standard, NZS 1170.5: Earthquake Actions, and a dedicated standard, NZS 4219: Seismic Performance of Engineering Systems in Buildings, address the seismic design of non-structural elements. This paper scrutinizes the design provisions for acceleration-sensitive non-structural elements in NZS 1170.5 and NZS 4219, and provides an international perspective by comparing with the design provisions for non-structural elements specified in ASCE 7-16, the latest ATC approach and Eurocode 8. This is followed by a detailed discussion on the improvements required for component demand estimation, the need for design criteria that are consistent with performance objectives, definition of realistic ductility factors, and recommendations for the future way forward in the form of an improved design procedure and its application through a new seismic rating framework.
\end{abstract}

\section{INTRODUCTION}

Good seismic design of a building requires an overarching approach that considers the influence of the structural and nonstructural design choices on the seismic performance of the building as a facility. Following the recent New Zealand (NZ) earthquakes, significant damage was reported to non-structural elements (NSEs) [1-3]. Such damage has led to considerable financial losses in the form of repair and business interruption costs. Research has shown that financial loss due to earthquakedamaged NSEs can be significantly more than the structural damage repair costs [4,5].

In New Zealand, there has been greater awareness of the importance of seismic design of NSEs in buildings as a result of the experience of 2010-2011 Canterbury earthquakes, the 2013 Seddon earthquake and the 2016 Kaikoura earthquake. These experiences provided the impetus to improve the seismic performance of non-structural elements (SPONSE), which in turn, has led to a significant amount of research on performance characterization of traditionally designed and installed NSEs, and laid the foundation for the development of low-damage designs for different NSEs [6-18]. Despite these efforts, the NZ construction industry still faces significant issues related to seismic design and installation of NSEs $[19,20]$. The past poor performance of NSEs has been identified as a system failure of the industry originating from inadequate procurement and tendering practices, design guidelines inconsistent with the state-of-the-knowledge, a lack of coordination among different NSE-related trades, faulty installations not identified due to poor quality control and noncompliance with existing standards and guidelines. While all of these issues must be addressed to ensure the improved seismic performance of NSEs, this paper focuses only on the seismic design aspects of acceleration-sensitive NSEs.

An acceleration-sensitive NSE is a building element that is sub- ject to the inertial forces resulting from the horizontal and vertical floor accelerations, but is not affected by the inter-story drift of the supporting structure. However, under the action of the inertial forces, the system itself and its seismic force resisting elements undergo deformations. Such deformations should be considered during the design stage as the majority of damage to such NSEs is because of unrestrained deformations [21]. These elements range from a single piece of equipment, mounted on or suspended from a floor, to a complicated network of interconnected components suspended from the floor, such as piping systems (Figure 1). This category of NSEs includes suspended ceilings, piping systems, cable trays, ducting, equipment, lighting, machinery and contents.
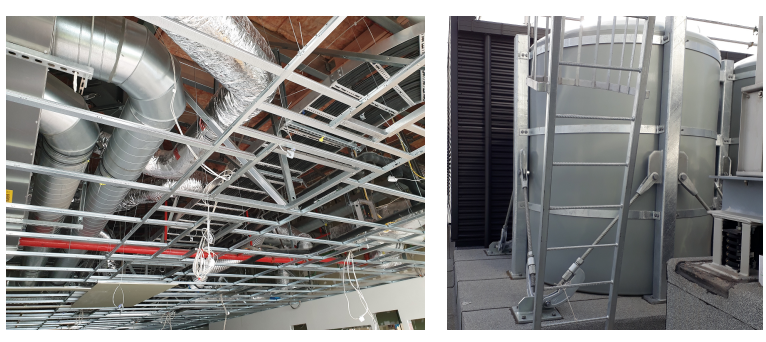

Figure 1: Acceleration-sensitive NSEs in a hospital building under construction: Suspended ceiling, piping, cable tray, ducts and roof mounted tanks.

The New Zealand Standard, NZS 1170.5: Earthquake Actions, dedicates a full section (Section 08) to the seismic design of NSEs [22]. This section primarily contains provisions regarding the determination of the design seismic force for parts and components, which includes acceleration-sensitive NSEs. Another dedicated standard, NZS 4219: Seismic Performance of Engineering Systems, addresses the seismic design of multiple

\footnotetext{
${ }^{1}$ PhD Candidate, University of Canterbury, muhammad.rashid@pg.canterbury.ac.nz (Student member)

${ }^{2}$ Professor, University of Canterbury, Christchurch, rajesh.dhakal@canterbury.ac.nz,(Fellow)

${ }^{3}$ Professor, University of Canterbury, Christchurch, timothy.sullivan@canterbury.ac.nz (Member)
} 
NSEs with design provisions and requirements for equipment, multiple piping systems, tanks and vessels, flues and stacks, ducting, hazardous substances, electrical and communication systems, luminaries and equipment supported by ceilings [23]. NSEs that are not included in NZS 4219 are covered by individual standards, such as: NZS 4541: Automatic Fire Sprinkler Systems [24], and AS/NZS 2785: Suspended Ceilings - Design and Installation [25].

Design standards typically provide equivalent static design force equations for the seismic design of NSEs. Such equations typically consist of the following terms:

i. Hazard factor: A term which represents the design acceleration (including the effects of soil type) at the base of the supporting building.

ii. Floor amplification factor: A term which accounts for the dynamic amplification of acceleration expected at a given floor relative to the acceleration at the base of the building.

iii. Component amplification factor: A term which accounts for the dynamic amplification of component acceleration relative to the floor acceleration to which it is attached.

iv. Risk or importance factor: A term which accounts for the individual importance of a component based on the consequences of its failure.

v. Ductility factor: A term which defines the allowed reduction in what would be an elastic design force by relying on the ductility capacity and over-strength of the seismic force resisting elements of a non-structural element.

The factors described above can be divided into two categories: demand and performance. The first three factors fall under the demand category as they define the magnitude of acceleration anticipated on a component. Together they form the design coefficient. The hazard factor is estimated using a probabilistic seismic hazard analysis framework. In contrast, the floor and component amplification factors appear to be mostly empirical in nature.

The risk or importance factor and the ductility factor fall into the performance category and appear to have been set based on judgment. The risk factor has been included to increase the design force above the anticipated demand (design coefficient), to enhance our confidence that the design will achieve its desired performance. Depending on the type and function of a specific component, the intent of the design provisions in the standards is to achieve one of the following performance objectives: i) to ensure life-safety, ii) to ensure functionality for operational continuity of essential facilities, and iii) to prevent consequential damage either from the component damage itself or from interaction with other building elements [22].

This paper examines thoroughly the seismic design provisions for acceleration-sensitive NSEs in two New Zealand standards: NZS 1170.5 and NZS 4219. It recommends improvements, within the existing framework of the current design procedure, which will assist in achieving the desired performance objectives. An international perspective is provided by presenting the design provisions in the ASCE 7-16 standard in the United States [26], the Eurocode 8 (EC-8) standard in Europe [27], and the latest Applied Technology Council approach [28]. This is followed by a detailed discussion on the improvements required for component demand estimation, the need for design criteria consistent with performance objectives, definition of realistic ductility factors, and recommendations for the future way forward in the form of an improved design procedure and its application through a new seismic rating framework.

\section{DESIGN STANDARDS FOR NON-STRUCTURAL ELEMENTS}

\section{NZS 1170.5:2004 (Incorporating Amendment No. 1)}

According to NZS 1170.5:2004 [22], the horizontal seismic design actions on a part or component can be determined using the following equation:

$$
F_{p h}=C_{p}\left(T_{p}\right) C_{p h} R_{p} W_{p} \leq 3.6 W_{p}
$$

where $C_{p}\left(T_{p}\right)$ is the horizontal design coefficient of the part and is given by:

$$
C_{p}\left(T_{p}\right)=C(0) C_{H i} C_{i}\left(T_{p}\right)
$$

The site hazard coefficient at $\mathrm{T}=0$ is equal to:

$$
C(0)=C_{h}(0) \operatorname{ZRN}(T, D)
$$

where, $T_{p}=$ period of the part, $C_{p h}=$ part horizontal response factor, $R_{p}=$ part risk factor, $W_{p}=$ weight of the part, $C_{H i}=$ floor height coefficient for level i, $C_{i}\left(T_{p}\right)=$ part spectral shape coefficient for level i, $C_{h}(0)=$ spectral shape factor at $T=0, Z=$ hazard factor, $R=$ return period factor, and $N=$ near-fault factor.

Different components that are typically installed in buildings have been classified into different categories (P1 to P7) based on the observed or perceived consequences of their failure, such as hazard to human life or the requirement for operational continuity of a facility (one component can have multiple categories [29]). Further, each category is assigned a design limit state (ULS, SLS1 or SLS2) and a part risk factor, $R_{p}$. The design limit state decides the value of the return period factor in Equation 1 above, which can vary from 0.25 to 1.8 depending on the importance level of the building in which the component is to be installed. The part risk factor, $R_{p}$, is equal to 1.0 for all categories except $\mathrm{P} 6$, in which case it is $2.0 R_{u}\left(R_{u}\right.$ is return period factor corresponding to ULS loading). Hence, both the component design limit state and the importance level of the building decide the component design force.

From the details above, the NZS 1170.5 approach implies that the same component is required to be designed for different demands in buildings of different importance levels. For example, a cladding system, which represents life-safety hazard to people outside the structure (category P1), will be designed for different levels of demand in an IL2 and an IL4 building at the same location, since the ultimate limit state (ULS) design demand for the two buildings differ because of different return period factors (1.0 vs. 1.8). Similarly, a ceiling system, which represents lifesafety hazard to people inside the structure (category P2 \& P3), will be designed for different design forces in an IL2 and an IL4 building. This implies different levels of seismic performance of the same NSE in buildings of different importance levels, if subjected to the same seismic hazard.

A comparison of the design forces for each of the seven component categories in an IL2 versus an IL4 building is provided in Table 1 and Table 2. Both structures are considered to be situated at the same location. All components are assumed to be located on the roof of a building with periods of vibration less than $0.75 \mathrm{~s}$ and a part response factor equal to 0.85 . It is clear that the design forces are higher for an IL4 building than an IL2 building, except for category P7, in which case the design forces are the same for both buildings, due to the same value of return period factor for SLS1.

Table C8.2 of NZS 1170.5 lists ductility capacity values for different types of parts and components. For a given component 
Table 1: Component seismic design forces on the roof of an IL2 building (ULS Hazard Level: 1/500) for Tp $<0.75$ s.

\begin{tabular}{|c|c|c|c|c|c|c|}
\hline \multirow{2}{*}{ Design Parameter } & \multicolumn{6}{|c|}{ Parts Category } \\
\hline & P1 & P2 \& P3 & P4 & P5 & P6 & P7 \\
\hline$Z$ & 0.4 & 0.4 & 0.4 & 0.4 & 0.4 & 0.4 \\
\hline$R$ & 1.0 & 1.0 & 1.0 & 0.5 & 0.25 & 0.25 \\
\hline$N$ & 1.0 & 1.0 & 1.0 & 1.0 & 1.0 & 1.0 \\
\hline$C_{h}(0)$ & 1.0 & 1.0 & 1.0 & 1.0 & 1.0 & 1.0 \\
\hline$C_{H i}$ & 3.0 & 3.0 & 3.0 & 3.0 & 3.0 & 3.0 \\
\hline$C_{i}\left(T_{p}\right)$ & 2.0 & 2.0 & 2.0 & 2.0 & 2.0 & 2.0 \\
\hline$C_{p}\left(T_{p}\right)$ & 2.4 & 2.4 & 2.4 & 1.2 & 0.6 & 0.6 \\
\hline$R_{p}$ & 1.0 & 1.0 & 1.0 & 1.0 & 2.0 & 1.0 \\
\hline$C_{p h}$ & 0.85 & 0.85 & 0.85 & 0.85 & 0.85 & 0.85 \\
\hline$C_{p}\left(T_{p}\right) \cdot R_{p} \cdot C_{p h}$ & 2.04 & 2.04 & 2.04 & 1.02 & 1.02 & 0.51 \\
\hline$F_{p h}=C_{p}\left(T_{p}\right) W \leq 3.60$ & $2.04 W$ & $2.04 W$ & $2.04 W$ & $1.02 W$ & $1.02 W$ & $0.51 W$ \\
\hline
\end{tabular}

Table 2: Component seismic design forces on the roof of an IL4 building (ULS Hazard Level: 1/2500) for Tp $<0.75$ s.

\begin{tabular}{|c|c|c|c|c|c|c|}
\hline \multirow{2}{*}{ Design Parameter } & \multicolumn{6}{|c|}{ Parts Category } \\
\hline & P1 & P2 \& P3 & P4 & P5 & P6 & P7 \\
\hline$Z$ & 0.4 & 0.4 & 0.4 & 0.4 & 0.4 & 0.4 \\
\hline$R$ & 1.8 & 1.8 & 1.8 & 1.0 & 0.25 & 0.25 \\
\hline$N$ & 1.0 & 1.0 & 1.0 & 1.0 & 1.0 & 1.0 \\
\hline$C_{h}(0)$ & 1.0 & 1.0 & 1.0 & 1.0 & 1.0 & 1.0 \\
\hline$C_{H i}$ & 3.0 & 3.0 & 3.0 & 3.0 & 3.0 & 3.0 \\
\hline$C_{i}\left(T_{p}\right)$ & 2.0 & 2.0 & 2.0 & 2.0 & 2.0 & 2.0 \\
\hline$C_{p}\left(T_{p}\right)$ & 4.32 & 4.32 & 4.32 & 2.4 & 0.6 & 0.6 \\
\hline$R_{p}$ & 1.0 & 1.0 & 1.0 & 1.0 & 3.6 & 1.0 \\
\hline$C_{p h}$ & 0.85 & 0.85 & 0.85 & 0.85 & 0.85 & 0.85 \\
\hline$C_{p}\left(T_{p}\right) \cdot R_{p} \cdot C_{p h}$ & 3.67 & 3.67 & 3.67 & 2.04 & 1.84 & 0.51 \\
\hline$F_{p h}=C_{p}\left(T_{p}\right) W \leq 3.60$ & $3.60 \mathrm{~W}$ & $3.60 \mathrm{~W}$ & $3.60 W$ & $2.04 W$ & $1.84 W$ & $0.51 W$ \\
\hline
\end{tabular}

ductility value, the part horizontal response factor, $C_{p h}$, can be determined from Table 8.2, which is calculated as the ratio of the structural performance factor, $S_{p}$, and the inelastic scaling factor, $k_{u}$. Section C8.6 allows the ductility values in Table C 8.2 to be superseded by ductility values verified through testing. It further requires that the ductility values should not be greater than 1.0 for SLS1 and 1.5 for SLS2, unless determined by special studies, in which case it should not be greater than 1.25 and 2.0 for SLS1 and SLS2, respectively.

\section{NZS 4219:2009}

NZS 4219 covers the design, construction and installation of seismic restraints for engineering systems, such as tanks and vessels, piping, ducting, and electrical and communication systems [23]. NZS 4219 provides two methods for seismic design of restraints for NSEs: non-specific and specific designs. All the discussion in this paper regarding NZS 4219 pertains to the non-specific design methodology. The specific design methodology requires earthquake actions to be determined in accordance with NZS 1170.5, whereas the actions on components and their restraints resulting from the differential movement of the supporting struc- ture shall be calculated based on structural mechanics.

The non-specific seismic design force in NZS 4219 is given by the following equation:

$$
F=C W
$$

The lateral force coefficient in the above equation is given as follows:

$$
C=2.7 C_{H} Z C_{p} R_{c} \leq 3.6
$$

where, $W=$ operating weight of the component, $Z=$ hazard factor, $C_{H}=$ floor height coefficient, $C_{p}=$ performance factor, and $R_{C}=$ component risk factor.

NZS 4219 employs a relatively simplified approach to calculate the design coefficient $\left(2.7 C_{H} Z\right)$. The coefficient 2.70 accounts for the combined effect of the site hazard coefficient $(C(0)$ in NZS 1170.5) and the component amplification factor. Further, the standard does not provide any guidance on the limiting deformation demands for NSEs that are not connected to the structure at more than one level or the procedure to determine them.

The component risk factor, $R_{c}$, accounts for the importance of the component, and similar to NZS 1170.5 , it is dependent on 
the parts category assigned to a component and the importance level of the building in which it is to be installed. This implies that a hazardous system, classified as P3, needs to be designed for a risk factor of 1.6 if it is to be installed in an IL4 building and for a risk factor of 0.9 for an IL2 building. A comparison of design forces based on NZS 4219 for all component categories in an IL2 versus an IL4 building is shown in Table 3 and Table 4. These comparisons rely on the same assumptions as those made in the previous section to compare the NZS 1170.5 design forces.

The design forces for categories P1, P2, P3 and P4 are higher for an IL4 building compared to an IL2 building. However, the design forces for the two buildings are the same for categories P5, P6 and P7 due to the same component risk factor across all building importance levels for categories P6 and P7. However, according to Table 5 of NZS 4219, the risk factor is not applicable to category P5 for IL1, IL2 and IL3 buildings on the assumption that there is no requirement to maintain operational continuity for these buildings; for an IL4 building the value assigned is 1.0 .

A comparison of the design forces for the two standards shows that NZS 4219 leads to higher forces than NZS 1170.5 except for category P6. However, the forces will be similar for cases where they both exceed $3.60 \mathrm{~W}$. The risk factors in NZS 4219 (Table 5) are not consistent with NZS 1170.5; for instance, the component risk factor in NZS 4219 for parts category P3 and an IL4 building is 1.60 , whereas the same according to NZS 1170.5 is $1.80\left(R_{p}=1 ; R=1.8\right)$. The amended NZS 1170.5 now has specified annual probabilities of exceedance for IL2 \& IL3 buildings for SLS2 with return period factors of 0.50 and 0.75 respectively; these values need to be added to Table 5 of NZS 4219 for the determination of the component risk factor.

In NZS 4219, the part performance factor, $C_{p}$, accounts for the ductility capacity of the seismic resisting elements. Table 4 in NZS 4219 shows that this factor is dependent on the importance level of the building as well as the parts category, though its dependence on building importance level is difficult to justify as the ductility capacity is dependent on the behavior of an element under cyclic loading. It is further required that the performance factor shall be applied separately to each part of a seismic restraint system rather than the whole system, for example, a brace element and its anchor shall be designed using their own respective performance factors. Appendix C in NZS 4219 lists the values of performance factor for a range of parts and components.

\section{ASCE 7-16}

The seismic design force for parts connected to a structure is given by the following equation in ASCE/SEI 7-16 [26]:

$$
\begin{gathered}
F_{p}=\frac{0.4 a_{p} S_{D S} W_{p}}{R_{p} / I_{p}}\left(1+2 \frac{z}{h}\right) \\
F_{p} \geq 0.3 S_{D S} I_{p} W_{p} \\
F_{p} \leq 1.6 S_{D S} I_{p} W_{p}
\end{gathered}
$$

where, $a_{p}=$ component amplification factor, $S_{D S}=5 \%$ damped design spectral response acceleration at short periods $(0.2 \mathrm{sec}-$ onds) per ASCE/SEI 7-16 and USGS at the project site, $W_{p}=$ component operating weight, $z=$ height in structure of point of attachment of component with respect to the base, $h=$ average roof height of structure with respect to the base, $R_{p}=$ component response modification factor, and $I_{p}=$ component importance factor.
Unlike NZS 1170.5, the design coefficient in ASCE 7-16 does not depend on the importance of the building. The component importance factor, $I_{p}$, is taken as 1.0 unless one of the following conditions apply: i) the component is required to function for life-safety purposes after an earthquake, including fire protection sprinkler systems and egress stairways, ii) the component conveys, supports or contains toxic or explosive substances, iii) the component is in Risk Category IV structure and is needed for continued operation of the facility, and iv) the component conveys, supports or contains hazardous substances and is attached to a structure classified as hazardous, in which case it is 1.5. Further, components with importance factor of 1.5 are called designated seismic systems, and the component itself needs to be designed for the calculated design forces (in addition to the bracing and anchorage systems).

Tables 13.5-1 and 13.6-1 provide values of $a_{p}$ and $R_{p}$ for a range of architectural, electrical and mechanical components, respectively. The value of $a_{p}$ is either 1.0 or 2.5 depending on the classification of the component as rigid or flexible, with the criterion for classification being vibration period lesser or greater than $0.06 \mathrm{~s}$, respectively. The ASCE 7-16 also allows for the calculation of $a_{p}$ using the National Center for Earthquake Engineering Research (NCEER) formulation as a function of the component and building vibration periods. For details, the reader is referred to ASCE 7-16 commentary section C13.3.

The component response modification factor, $R_{p}$, accounts for inherent reserve strength in a component in addition to ductility, and varies from 1.0 to 12.0 , with 12.0 being assigned to welded steel piping systems. It is worth noting here that using an $R_{p}$ value equal to 12.0 would require the use of the minimum value of the design force as given by Equation 7.

\section{ATC Approach}

The Applied Technology Council in the USA has recently proposed a design force equation that is based on recorded building floor motions and numerical investigations [28]. The variation in component design force was investigated for the following parameters: i.) peak ground acceleration, $P G A$; ii.) seismic force-resisting system of the building, $S F R S$; iii.) building's modal periods, $T_{n b l d g}$; iv.) building ductility, $\mu_{b l d g}$; v.) inherent building damping, $\beta_{\text {bldg }}$; vi.) building configuration, $I R R$; vii.) floor diaphragm rigidity, DIA; viii.) vertical location of component within the building, $z / h$; ix.) component period, $T_{\text {comp }}$; x.) component and/or anchorage ductility, $\mu_{\text {comp }}$; xi.) inherent component damping, $\beta_{\text {comp }}$; and xii.) component overstrength, $\Omega_{\text {Ocomp }}$.

The design force equation resulting from the ATC approach is given below:

$$
\frac{F_{p}}{W_{p}}=P G A \times\left[\frac{\left(\frac{P F A}{P G A}\right)}{R_{\mu b l d g}}\right] \times\left[\frac{\left(\frac{P C A}{P F A}\right)}{R_{\text {pocomp }}}\right] \times I_{p}
$$

The floor amplification factor is given as follows:

$$
\begin{gathered}
\frac{P F A}{P G A}=1+a_{1}\left[\frac{z}{h}\right]+a_{2}\left[\frac{z}{h}\right]^{10} \\
a_{1}=\frac{1}{T_{\text {abld }}} \leq 2.5 \\
a_{2}=\left[1-\left(\frac{0.4}{T_{\text {abldg }}}\right)^{2}\right]>0
\end{gathered}
$$

where, $W_{p}=$ component operating weight, $P G A=$ peak ground acceleration $\left(0.4 S_{D S}\right), P F A=$ peak floor acceleration, $R_{\mu b l d g}=$ 
Table 3: Component seismic design forces on the roof of an IL2 building (ULS Hazard Level: 1/500).

\begin{tabular}{cccccccc}
\hline \multirow{2}{*}{ Design Parameter } & \multicolumn{9}{c}{ Parts Category } \\
\cline { 2 - 8 } & P1 & P2 & P3 & P4 & P5 & P6 & P7 \\
\hline$Z$ & 0.4 & 0.4 & 0.4 & 0.4 & 0.4 & 0.4 & 0.4 \\
$2.7 C_{H}$ & $2.7 \times 3.0$ & $2.7 \times 3.0$ & $2.7 \times 3.0$ & $2.7 \times 3.0$ & $2.7 \times 3.0$ & $2.7 \times 3.0$ & $2.7 \times 3.0$ \\
$R_{c}$ & 1.0 & 1.0 & 0.9 & 1.0 & - & 0.5 & 0.25 \\
$C_{p}$ & 0.85 & 0.85 & 0.85 & 0.85 & 0.85 & 0.85 & 0.85 \\
$C$ & 2.75 & 2.75 & 2.48 & 2.75 & 2.75 & 1.38 & 0.69 \\
$F_{p h}=C_{p} W \leq 3.60$ & $2.75 W$ & $2.75 W$ & $2.48 W$ & $2.75 W$ & $2.75 W$ & $1.38 W$ & $0.69 W$ \\
\hline
\end{tabular}

Table 4: Component seismic design forces on the roof of an IL4 building (ULS Hazard Level: 1/2500).

\begin{tabular}{ccccccccc}
\hline \multirow{2}{*}{ Design Parameter } & \multicolumn{9}{c}{ Parts Category } \\
\cline { 2 - 8 } & P1 & P2 & P3 & P4 & P5 & P6 & P7 \\
\hline$Z$ & 0.4 & 0.4 & 0.4 & 0.4 & 0.4 & 0.4 & 0.4 \\
$2.7 C_{H}$ & $2.7 \times 3.0$ & $2.7 \times 3.0$ & $2.7 \times 3.0$ & $2.7 \times 3.0$ & $2.7 \times 3.0$ & $2.7 \times 3.0$ & $2.7 \times 3.0$ \\
$R_{C}$ & 1.8 & 1.8 & 1.6 & 1.8 & 1.0 & 0.5 & 0.25 \\
$C_{p}$ & 0.85 & 0.85 & 0.85 & 0.85 & 0.85 & 0.85 & 0.85 \\
$C$ & 4.96 & 4.96 & 4.40 & 4.96 & 2.75 & 1.38 & 0.69 \\
$F_{p h}=C_{p} W \leq 3.60$ & $3.60 W$ & $3.60 W$ & $3.60 W$ & $3.60 W$ & $2.75 W$ & $1.38 W$ & $0.69 W$ \\
\hline
\end{tabular}

reduction factor to account for building global ductility, $R_{\text {pocomp }}$ $=$ inherent component reserve strength margin factor, $I_{p}=$ component importance factor, $z=$ height in structure of point of attachment of component with respect to the base, $h=$ average roof height of structure with respect to the base, and $T_{a b l d g}=$ the approximate fundamental translational period of the building per ASCE/SEI 7-16 equation 12.8-7.

Unlike ASCE 7-16, where the floor amplification factor increases linearly to three times the ground acceleration at the roof of a building, a nonlinear equation for $P F A / P G A$ is proposed in the ATC approach that depends on $z / h$ and $T_{a b l d g}$ (Equation 10). The component amplification factor, $P C A / P F A$, is proposed to be dependent on the component location in the building, the likelihood of a component being in resonance with the building and the component ductility. Depending on these parameters, the component amplification factor can take on values ranging between 1.4 and 4.0. For further details, the reader is referred to NIST [28]. The ATC design force equation will be included in the next edition of the ASCE 7 Standard (ASCE 7-22).

\section{Eurocode 8}

According to Eurocode 8 (EC-8) [27], the horizontal equivalent static design force to be applied at the component's center of mass in the most unfavorable direction is given by:

$$
F_{a}=\frac{S_{a} W_{a} \gamma_{a}}{q_{a}}
$$

The seismic coefficient, $S_{a}$, is given by the following expression:

$$
S_{a}=\alpha S\left(\frac{3(1+z / H)}{1+\left(1-T_{a} / T_{1}\right)^{2}}-0.5\right) \geq \alpha S
$$

where, $W_{a}=$ weight of the component, $\gamma_{a}=$ importance factor of the component, $q_{a}=$ behavior factor for the component, $\alpha$ $=$ ratio of design ground acceleration, $a_{g}$, to acceleration due to gravity, $g$ (typically corresponding to shaking intensity with
$10 \%$ probability of exceedance in 50 years), $S=$ soil factor, $H$ $=$ building height measured from the foundation or from the top of a rigid basement, $z=$ height of the structural component to which the NSE is attached above the level of application of the seismic action (foundation or top of a rigid basement), $T_{a}=$ fundamental vibration period of the non-structural component, and $T_{1}=$ fundamental vibration period of the building in the relevant direction.

Unlike other standards, the component amplification factor is dependent on the proximity of the component and supporting structure vibration period $\left(T_{a} / T_{1}\right)$. The importance factor is normally 1.0, except it is taken as 1.5 for the following components: i) anchorage elements of machinery and equipment required for life-safety systems, and ii) tanks and vessels containing toxic or explosive substances considered to be hazardous to the safety of the general public. The value of the behavior factor is given for a limited number of components and ranges from 1.0 to 2.0. It is important to mention here that some European standards have recently adopted new design force formulations for seismic design of NSEs; one such example is the recent Italian regulations NTC 2018 [30].

\section{Comparison of Different Design Standards}

An overview of international design standards reveals that the basic structure of the equivalent static design force equation is similar to the NZ standards. Principal differences lie in the way the demand and performance factors are defined. The following three points are made:

i. In all the design standards, the ground and floor accelerations are amplified by empirical coefficients to compute the component acceleration. These coefficients are independent of the building and component dynamic characteristics, except for EC-8, wherein consideration is given to the proximity of the building and component periods of vibration. The ASCE 7-16 also allows the use of the NCEER formula- 
tion for the calculation of component amplification factor $\left(a_{p}\right)$ as an alternative to the tabulated values of $a_{p}$.

In the NZ standards and ASCE 7-16, the floor and component amplification factors are separately defined, whereas EC-8 provides a single equation that accounts for the floor and component amplification to compute the component acceleration. None of the standards considers the building non-linearity and the component damping as a variable in the estimation of acceleration demand. It is also important to mention here that of all standards discussed herein, only the NZS 1170.5 and ASCE 7-16 have provisions for vertical seismic design of NSEs.

ii. The range of risk or importance factor values is almost the same across the different standards. ASCE 7-16 assigns importance factor values to a considerable number of NSEs, followed by NZ standards, with EC-8 providing relatively limited information.

iii. As will be explained through the example below, the application of the ductility factor (also called response or performance factor, strength reduction factor or behavior factor) is conceptually different for the same system in the different standards. ASCE 7-16 lists R-factors for a considerable number of NSEs followed by NZ standards, and EC-8 providing relatively limited information. Also, ASCE 7-16 provides $\mathrm{R}$-factors as high as 12.0 , while the corresponding values in NZS 1170.5, NZS 4219 and EC-8 are $2.22(1 / 0.45), 4.0(1 / 0.25)$ and 2.0, respectively. The ductility factor in the NZ standards is multiplied into the design coefficient $(<1)$, whereas in ASCE 7-16 and EC-8 these are in the denominator $(>1)$ of the design force equation.

The demand and performance terms of the design force equations in the different standards are given in Table 5. A comparison of the elastic design spectra for the different standards is shown in Figure 2. For EC-8, $T_{a}$ and $T_{1}$ are equal to $1.0 \mathrm{~s}$. It can be seen that the standards differ widely in estimating the component design coefficient along the period axis. ASCE 7-16 provides a constant design coefficient beyond the component vibration period of $0.06 \mathrm{~s}$, whereas NZS 1170.5 and EC-8 estimates vary with the vibration period. Further, ASCE 7-16 provides higher design coefficient beyond $0.06 \mathrm{~s}$ as compared to the other two standards.

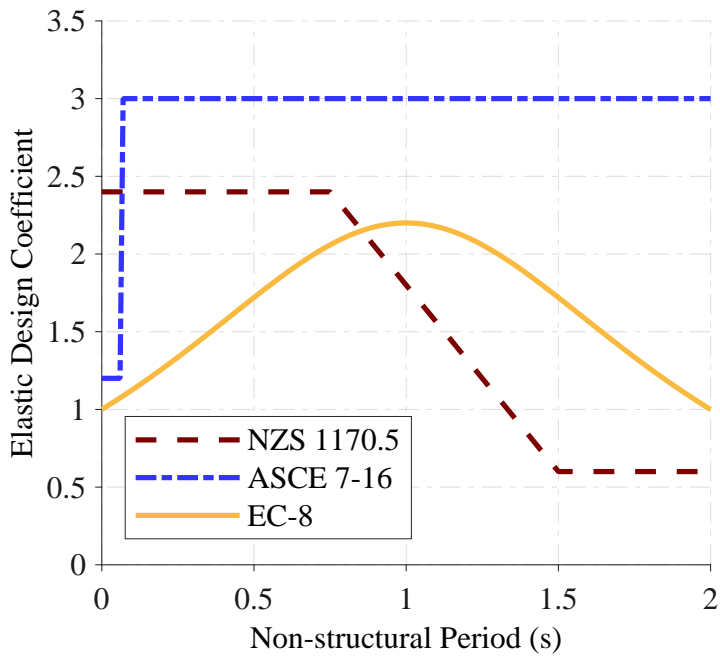

Figure 2: Comparison of the elastic design spectra for components derived using different standards for a peak ground acceleration of $0.4 \mathrm{~g}$.
The design forces for components according to the different standards might not follow the same pattern, as shown in Figure 2, due to the specification of different performance factors. Consider a piping system with threaded connections containing hazardous material to be installed at the roof of a highly important or a high risk building, which is located at a site with a design seismic hazard (10\% probability of exceedance in 50 years) of $0.4 \mathrm{~g}$ (soil factors considered $=1.0$ ). Assume that the piping vibration period is $0.75 s>T_{p}>0.06 s$ and is quite close to the fundamental period of the supporting structure. The seismic resisting system of the piping consists of sway braces. Following the description above, the design seismic force for the piping system is calculated using the available information in the standards discussed herein and is presented in Table 6 .

In this particular case, the calculated design force is the least when using the ASCE 7-16 provisions. This is due, primarily, to the relatively high force reduction factor accounting for ductility. However, the relative difference in the design force calculated using each of the individual standards will vary from component to component. It will also depend on the performance factors used for the component in consideration.

Of all the design factors, the ductility factor has the least guidance in the standards. For instance, NZS 1170.5 and ASCE 7-16 provide ductility factors for different types of pipes only and not the bracing systems. Although the ductility classification in NZS 1170.5 is based on the functionality of the pipe (water supply, pressure etc.), ASCE 7-16 assigns the ductility factor based on the type of connections (threaded and welded etc.) and piping material. The $C_{p h}$ value for pipes is 0.55 in NZS 1170.5, and an $R_{p}$ equal to 4.5 is recommended for piping with threaded connections in ASCE 7-16. On the other hand, NZS 4219 provides ductility factor $\left(C_{p}\right)$ values for both bracing systems and piping connection types; a $C_{p}$ value equal to 0.85 is given for bracing systems in NZS 4219, which has been used in the example. EC8 provides no guidance on the ductility factor for piping systems whatsoever and that is why $q_{a}$ equal to unity has been used in the piping example.

\section{DEMAND FACTORS}

When a structure is subjected to an earthquake ground excitation, the resulting frequency and amplitude characteristics of a floor response will be dependent on the modal vibration periods, damping and the non-linearity of the supporting structure [28,3236]. The variation in frequency and amplitude characteristics of one floor response relative to another is dependent on the modes of vibration exciting those floors. The NSEs attached to a floor have their own dynamic characteristics, and when a supporting floor vibrates under the influence of a ground motion, the acceleration demand on the attached component will be dependent on the proximity of the component vibration period to a modal period of the structure and the component damping.

Traditionally, in design standards, the considerations described above are divided into two factors, which ensures ease of application: i) the floor amplification factor, and ii) the component amplification factor. The floor amplification factor is a simplified and empirical representation of the variation of peak floor accelerations along the height of a building. Theoretically, the total floor acceleration at any height of the building responding elastically is described by the equation below given in Miranda and Taghavi [32].

$$
\ddot{u}^{t}(x, t)=\ddot{u_{g}}(t)+\sum_{i=1}^{m} \Gamma_{i} \phi_{i}(x) \ddot{D}_{i}(t)
$$

where, $\ddot{u}^{t}(x, t)=$ total floor acceleration at non-dimensional height $x, \ddot{u}_{g}(t)=$ ground acceleration, $\Gamma_{i}=$ modal participation 
Table 5: Demand and performance factors for acceleration-sensitive NSEs in the design standards discussed herein.

\begin{tabular}{ccccc}
\hline Design Parameter & NZS 1170.5 & NZS 4219 & ASCE 7-16 & EC-8 \\
\hline Site Hazard & $C(0)$ & $2.7 Z$ & $0.4 S_{D S}$ & $\alpha S$ \\
Floor Amplification Factor & $C_{H i}$ & $C_{H}$ & $(1+2(z / h))$ & $\left(\frac{3(1+z / H)}{1+\left(1-T_{a} / T_{1}\right)^{2}}-0.5\right)$ \\
Component Amplification Factor & $C_{i}\left(T_{p}\right)$ & Undefined & $a_{p}$ & $\gamma_{a}$ \\
Risk/Importance Factor & $R_{p}(R)$ & $R_{c}$ & $I_{p}$ & $q_{a}$ \\
Ductility Factor & $C_{p h}$ & $C_{p}$ & $F_{p}$ & $F_{a}$ \\
Design Force & $F_{p h}$ & $F$ & &
\end{tabular}

Table 6: Estimates of design forces for a roof-top piping system using the design standards discussed herein.

\begin{tabular}{ccccc}
\hline Design Parameter & NZS 1170.5 & NZS 4219 & ASCE 7-16 & EC-8 \\
\hline Hazard Factor & $Z=0.4$ & $Z=0.4$ & $S_{D S}=1.0$ & $\alpha=0.4$ \\
Floor Amplification Factor & $C_{H i}=3.0$ & $C_{H}=3.0$ & 3.0 & 5.5 \\
Component Amplification Factor & $C_{i}\left(T_{p}\right)=2.0$ & Undefined & $a_{p}=2.5$ & $I_{p}=1.5$ \\
Risk/Importance Factor & $R_{p}=1 ;(R=1.8)$ & $R_{c}=1.8$ & $R_{p}=4.5$ & $\gamma_{a}=1.5$ \\
Ductility Factor & $C_{p h}=0.55$ & $C_{p}=0.85$ & $F_{p}=1.0 W_{p}$ & $F_{a}=3.3 W_{a}$ \\
Design Force & $F_{p h}=2.38 W_{p}$ & $F=3.60 W$ & &
\end{tabular}

factor of the $i^{t h}$ mode of vibration, $\phi_{i}(x)=$ amplitude of the $i^{\text {th }}$ mode shape of vibration at non-dimensional height $x, \ddot{D}_{i}(t)=$ relative acceleration of the $i^{\text {th }}$ mode SDOF system.

Equation 15 implies that the total floor acceleration depends on the modal properties of the structure and can vary from floor to floor within a building. It also depends on the ground shaking, which can be critical at long periods and at lower levels of a building [36,37]. Figure 3 is an illustration of Equation 15, obtained numerically, which shows that the distribution of peak floor accelerations not only varies across buildings with different dynamic characteristics but also within a single building type [31]. The observation that the distribution of floor accelerations over the height of the building does not follow a specific profile has been validated in numerous studies [31,33,38]; this is rightly so because the dynamic response of a multi-story building is dominated by more than one vibration mode.

NZS 1170.5 has a pre-defined floor amplification factor that does not consider the building dynamic characteristics. As shown by Figure 4 , it increases linearly up to $0.2 h_{n}$ or $12 \mathrm{~m}$ of the building height and then assumes a constant value of 3.0 up to the roof. This is thought to be supported by the study of Rodriguez et al. [39]. Using numerical investigations, Uma et al. [38] have shown that floor accelerations can be much less than those resulting from the floor height coefficient in NZS 1170.5; however, they also recommend further investigation as their study was limited in its scope.

The previous reasoning related to vibration modes is only true if the building is not responding in the non-linear range. Since structures are designed for forces smaller than those needed for elastic response under rare shaking intensity levels, it is expected that structures will yield during the ultimate limit state design intensity shaking and may experience smaller accelerations than if the response were elastic. Of the design standards discussed herein, only the ATC approach considers the influence of the supporting structure non-linearity on the component acceleration demands [28]. The reader is referred to Sullivan et al. [35],
Medina et al. [40],Ray-Chaudhuri and Hutchinson [41],Anajafi and Medina [42] for further details on this issue.

The component amplification factor accounts for the difference in component acceleration amplitude relative to the peak floor acceleration to which it is attached. Figure 4 shows the spectral shape coefficient (component amplification factor in NZS 1170.5), which is given as a simplified floor response spectrum and has a peak value of 2.0 for component vibration periods less than or equal to $0.75 \mathrm{~s}$. Multiple studies on instrumented buildings, numerical models and experimental investigations have shown that the amplifications can be well in excess of 2.0 [35-37,42-44].

More importantly, the magnitude of amplification is dependent on the proximity of the vibration periods of the supporting structure to the component period (rather than just the period of the component) and both the component and supporting structure damping [45]; hence, a fixed value for amplification cannot be justified. Figure 5 shows the response spectra of a recorded floor motion in New Zealand for damping ratios of $2.0 \%$ and $5.0 \%$. The maximum dynamic amplification (i.e., at the spectral peak) is evident at the vibration period of 0.60 s (fundamental building period) and is equal to 9.25 and 5.9 for $2.0 \%$ and $5.0 \%$ damping, which in both cases is considerably higher than the maximum value of 2.0 in NZS 1170.5. The influence of damping should be noted because the amplification for $2.0 \%$ damping is 1.56 times that calculated for $5.0 \%$ damping. This implies that two components with the same vibration period and attached to the same floor will have different acceleration demands if their damping is different.

The authors also recommend investigating the peak acceleration demands on components that are mounted on the walls rather than attached to building floors, for example, wall-mounted patient monitors in hospitals. Retamales et al. [46] found that such equipment experiences dynamic amplification due to the flexibility of the partition walls to which these are attached.

A more rational approach to the estimation of component ac- 

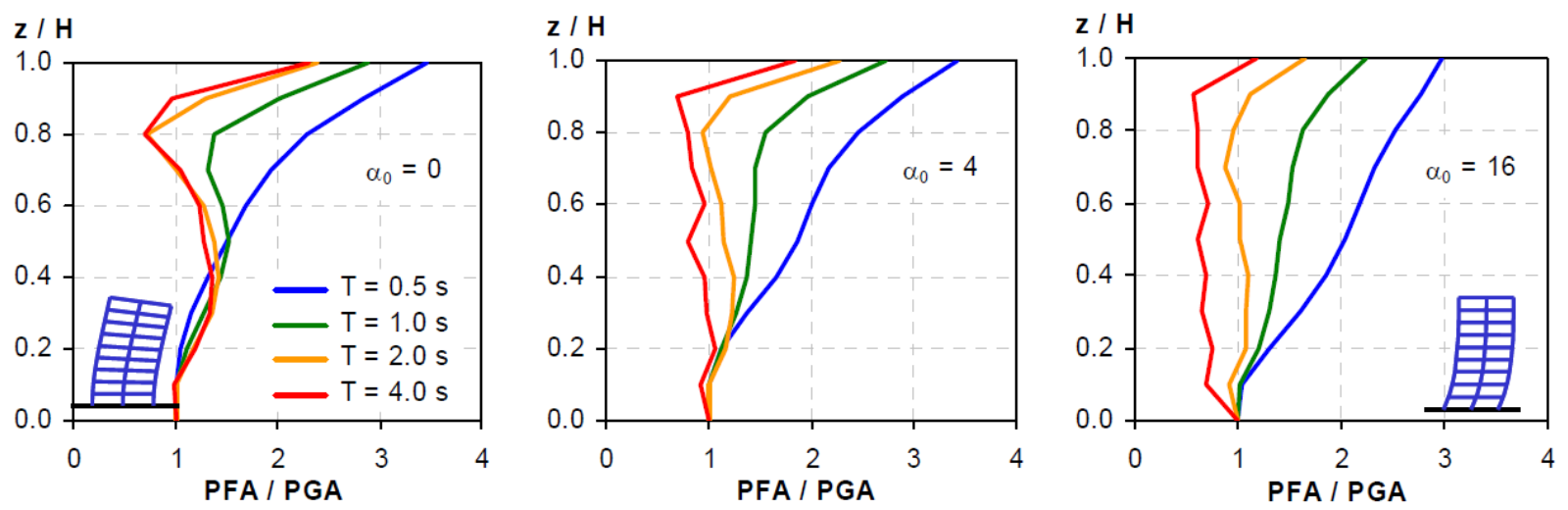

Figure 3: Variation in peak floor acceleration demands in buildings with different vibration periods and structural systems with different lateral deflection profiles. The dimensionless parameter, $\alpha_{o}$, is the lateral stiffness ratio, which controls the lateral deflection profile of the structure by controlling the degree of participation of flexural and shear deformations [31].

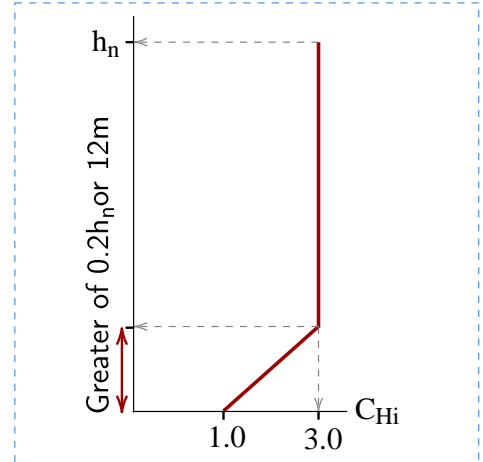

(a) Floor height coefficient

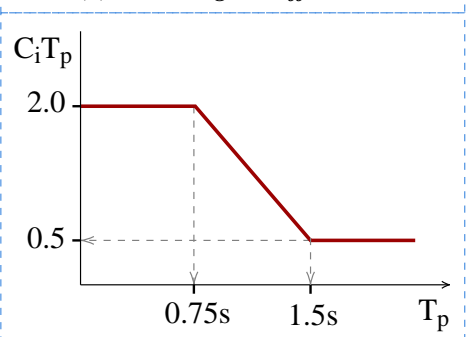

(b) Spectral shape coefficient

Figure 4: Floor height coefficient $\left(C_{H i}\right)$ and spectral shape coefficient $\left(C_{i}\left(T_{p}\right)\right)$ according to NZS 1170.5 [22].

celeration demands that takes into account the proximity of vibration periods of the supporting structure and the component, and is adjustable for different damping ratios, should be adopted. Recently, Haymes et al. [37] proposed an alternative method for estimating component acceleration demands accounting for building and component vibration periods and damping. This procedure recommends that if only the fundamental structural mode is considered, the floor response spectrum should be set equal to the maximum of ground level spectrum and the product of peak floor acceleration and dynamic amplification factor, as given by Equation 16. For consideration of multiple modes of vibration, the floor response spectrum is set equal to the maximum of ground level spectrum and the square-root-sum-of-squares of the modal contributions. The maximum dynamic amplification occurs at a component period $\left(T_{N S}\right)$ to building period $\left(T_{s t r}\right)$ ratio near 1.0, which indicates resonance.

$$
S_{F A}\left(T_{N S}, \zeta_{N S}\right)=\max \left[S_{G A}\left(T_{N S}, \zeta_{N S}\right), P F A \times D A F\left(r_{T, i}\right)\right]
$$

ing to component period $T_{N S} \&$ damping $\zeta_{N S}, S_{F A}=$ spectral floor acceleration ordinate corresponding to component period $T_{N S} \&$ damping $\zeta_{N S}, P F A=$ peak floor acceleration, $D A F\left(r_{T, i}\right)$ $=$ dynamic amplification factor describing resonant behavior between the building modal period and the component period, where the subscript $r_{T, i}$ denotes the ratio of component to building vibration periods.

The variation of DAF with the period ratio is illustrated in Figure 6 , where the period ratios can either be taken from ASCE/SEI 7-16 [26] or the ratios adopted by Haymes et al. [37] can be used.

The maximum dynamic amplification factor can be approximated by the following expression as given in Haymes $e t$ al. [37]:

$$
D A F_{\max }=\left[0.5 \zeta_{s t r}+\zeta_{N S}\right]^{-2 / 3} \approx \frac{1}{\sqrt{\zeta_{N S}}}
$$

where, $\zeta_{s t r}=$ structural damping, and $\zeta_{N S}=$ non-structural damping.

For a typical structural and non-structural damping value of $5.0 \%$, Equation 17 results in an amplification of around five times the peak floor acceleration, which is considerably larger than the maximum amplification of 2.0 given in NZS 1170.5 (Figure 4).

The accuracy of the proposed procedure was assessed by comparing its predictions with the floor response spectra of instrumented buildings in New Zealand [47]. As shown in Figure 7 as an example, the proposed method predicts the floor response spectra quite reliably. Further, Figure 7 demonstrates that the spectral shape coefficient given in NZS 1170.5 underestimates the component acceleration demands at periods corresponding to the building vibration periods. This means that a component designed using the spectral shape coefficient given in NZS 1170.5 may be under-designed if its period is close to a building modal period. However, if the component is braced or isolated so that resonance is avoided, its design may be overly conservative. This finding emphasizes the need to modify the spectral shape coefficient to account for the proximity of the building and component vibration periods in estimating the component acceleration demands. The reader is referred to Vukobratović and Fajfar [34],Fathali and Lizundia [43],Kazantzi et al. [48],Merino et al. [49] for other methods recently developed for the estimation of component acceleration demands. 


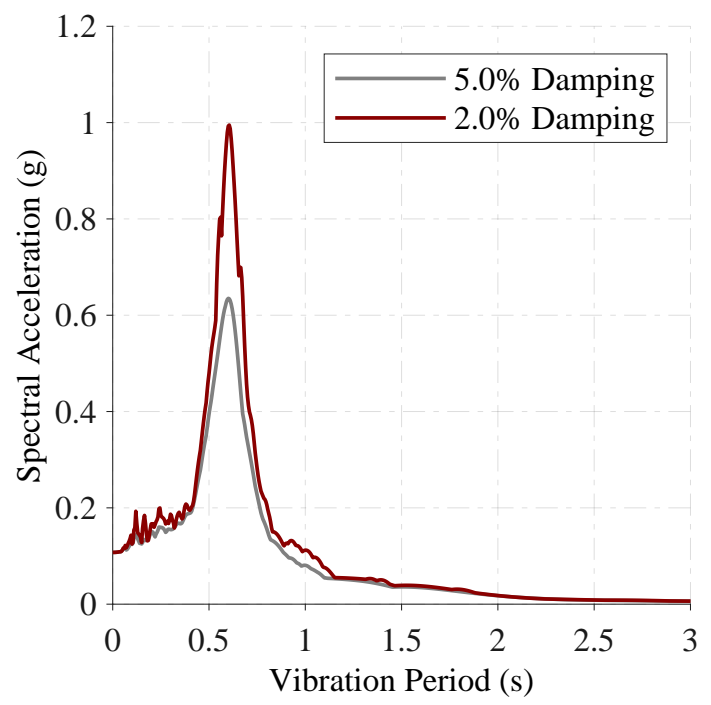

Figure 5: Response spectra of a recorded floor motion in UC Physics building, Christchurch NZ, illustrating the influence of component damping on spectral acceleration demands.

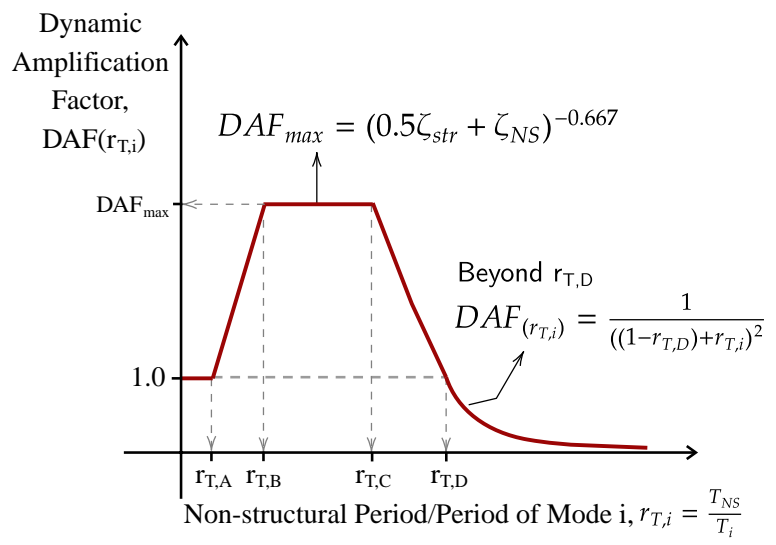

Figure 6: Variation of the proposed dynamic amplification factor with the period ratio for a given vibration mode $i$ [37].

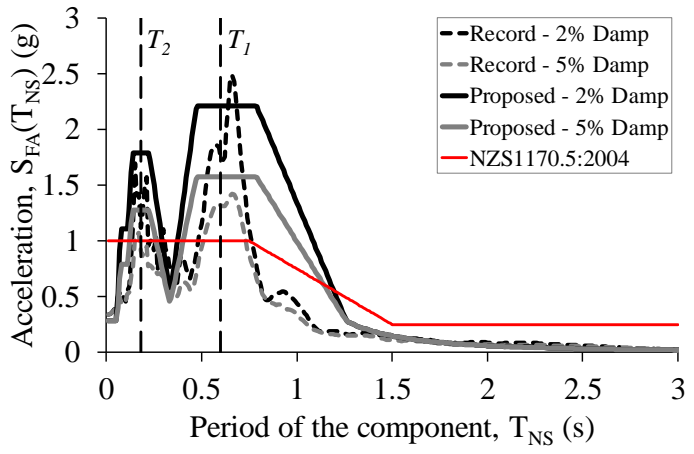

Figure 7: Comparison of the response spectra of a recorded floor motion for damping ratios of $2.0 \%$ \& $5.0 \%$ with predictions of the same using the procedure proposed by Haymes et al. [37].

As stated earlier, the use of robust procedures to estimate the component acceleration demand requires the determination of component period of vibration and damping. Further research is needed to determine the periods of vibration of different components and their damping. For components that do not change in configuration or geometry across different applications, the determination of period could be straightforward, and could be taken from seismic qualification testing or analytical methods. For components with varying configurations, such as piping systems, the period of vibration will vary from one application to another. In such cases, simplified analytical expressions or calibrated numerical models appear best suited to determine the periods, or resonance could be conservatively assumed for design.

Unlike the period of vibration, damping can only be determined using experiments. Given the broad range of NSEs and their different restraints and mounting conditions, a wide spectrum of damping ratios could be anticipated. This can be confirmed from studies that have determined the damping ratio of multiple NSEs through in-situ testing conducted in actual buildings. Watkins et al. [50] conducted impact hammer testing of various equipment including tanks, compressors, transformers, boiler, control panels, etc., and found that the damping ratio varied between $0.67 \%$ and $4.9 \%$ of critical with a mean of $2.1 \%$. Archila et al. [51], through operational and forced vibration testing, calculated the damping ratio for various NSEs. The damping ratio for pipes varied from $0.4 \%$ to $2.61 \%$ for the fundamental mode. In the same study, the damping ratio for an air handler unit, two electric panels and a transformer was found to be $0.18 \%, 0.15 \%, 0.26 \%$, and $0.39 \%$. Yang [52] tested installed NSEs consisting of pumps, an air handler unit, relay rack, dry air vacuum, medical air power unit, pump assembly, vertical pipe, medical air cylinder rack, and service air vacuum unit. The damping ratio varied from $1.3 \%$ to $8.9 \%$.

Given the wide range of damping ratios for typical NSEs and the influence that damping has on acceleration demand, it is recommended that a demand estimation procedure that accounts for the influence of damping should be adopted, such as the procedure proposed by Haymes et al. [37].

\section{PERFORMANCE FACTORS}

\section{Objective Performance \& Risk Factors}

Due to the variability in a structure's mechanical and dynamic characteristics, and the randomness of seismic excitation, the predicted response of a component, and thus the level of protection against damage, contains uncertainty. The risk or importance factor serves to increase the design forces for essential components and systems above the limit defined by the design coefficient. This is done as an indirect way of ensuring (through higher design forces) that the system performs according to the performance objective stipulated in the standards.

There are a number of reasons why the design of NSEs, given the current state of design standards and practice, needs more than just higher design forces if objective performance is the goal. There is a major difference between structural and non-structural systems in that the structural system itself is the seismic resisting system, whereas for NSEs, the system and seismic resisting elements are separate. For instance, in a distributed system like piping, the interconnected pipes make up the system whereas the braces provide seismic resistance. Hence, any design procedure must address the performance of the system and the force resisting elements under the design forces and deformations. The two major requirements for the design of NSEs should be: i) strength, e.g., estimation of design anchorage force for floor mounted equipment or a pipe brace and, ii) deformation limits, e.g., allowable displacement for a piping segment to avoid connection damage or interaction.

The reliability of any estimate of the required strength is dependent on the robustness of the component acceleration demand estimate, which has already been considered in the previous 
section. However, if proprietary products are used, without any due consideration to the seismic demand or capacity, the implied safety in the design standards through the use of reliable strength estimates will not be translated into practice. For instance, suspended ceilings are classified as category P2 \& P3 systems in NZS 1170.5, and need to be designed for ULS loading (higher $\mathrm{R}$ factor) because if the panels fall off the grids, they may cause injuries or block egress ways. Nevertheless, failure of suspended ceilings is a common observation after earthquakes [1-3].

Dhakal et al. [53] estimated the seismic demand on typical NZ ceiling grids in accordance with NZS 1170.5. They compared it with the capacities of different components of a ceiling grid characterized by fragility functions derived from component tests (Figure 8). It was found that of all the components, cross-tee and perimeter connections were the most vulnerable to damage: that is, the grid system for supporting panels is as strong as its cross-tee and perimeter connections. Dhakal et al. [53] further showed that depending on the tributary seismic mass of the grids, the capacity of the grid components can fall short of the demand by a considerable margin.

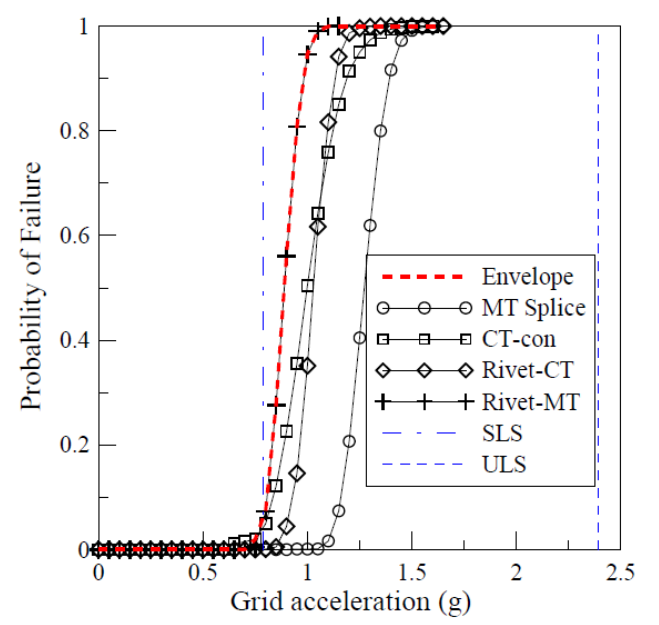

Figure 8: Fragility curves for typical components of a ceiling grid tested in NZ [53]. The NZS 1170.5 ULS acceleration demand clearly exceeds the capacity of the ceiling system.

The introduction of proper design procedures and simple mitigation measures, like grid clips on inter-grid connections and double rivets for perimeter connections (for enhanced strength \& ductility), can substantially improve the seismic performance of these systems and thus increase the reliability of these systems.

The requirement of deformation limits applies to distributed systems, unless individual components, such as equipment, are inherently flexible, in which case deformations may become a concern. The current standards do not provide any guidance about how to determine the deformation demands for components that are not connected to the structure at more than one level. Likewise, deformation limits are not defined to achieve a performance target. For instance, NZS 4219 requires that liquid fuel and water piping should be functional at the design loading specified. Similarly, NZS 4541 requires sprinkler piping to be functional at the ultimate limit state (ULS) loading of the building in which it is installed. However, examination of the design standards reveals that, with the exception of design forces and ductility factors, there are no suitable damage-related criteria (e.g., deformation limits) specified, nor rational design requirements. Empirical criteria (such as restraint-spacing/300 $\leq 50 \mathrm{~mm}$ ) form the basis for brace spacing limits in NZS 4219, without any apparent technical basis related to seismic forces and brace properties.

Another concern for distributed systems is the clearance around these elements to avoid interaction with the surrounding building elements. Such interaction can lead to mutual damage, which might affect the functionality of the system and cause consequential damage, as shown in Figure 9. Given the lack of evidence, it seems that the existing clearance requirements in the standards are also based on judgment. Clearly, these need to be reviewed based on evidence presented in research studies such as Soroushian et al. [54].
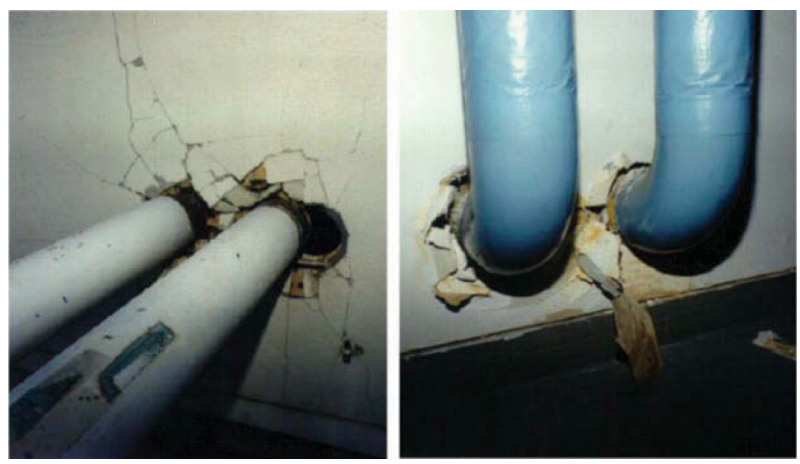

Figure 9: Piping damage at penetration joints shown as an example of damage due to lack of proper clearance [54].

The current component risk factors in the design standards do not appear to be based on component performance in past earthquakes, nor do they appear to be based on experimental or analytical investigations. To establish risk factors, the acceptable probability of failure or exceedance of a damage state needs to be decided first. Further, risk factors should consider the fragility of components and systems, and account for uncertainty in component capacity and performance.

Finally, components which can cause injury or present threat to human life (i.e., categories P1-P3 as per NZS 1170.5) are currently designed for significantly less seismic forces in an ordinary building than in important buildings. This gives the impression that a person's life becomes less valuable when he or she is at residence than at a work place categorized as an important building. It may be considered reasonable for such components to have the same safety margin against failure irrespective of the building importance level (i.e., whether these are installed in an ordinary or important building).

As regards components and systems that are essential for operational continuity of a facility (category P5 as per NZS 1170.5), the operational requirements of different building categories are different, and therefore, such components may need to be designed for different levels of force in different building typologies. This can be accommodated by assigning risk factors on an individual basis. Currently, the same outcome is being achieved by using the same component risk factor for different importance levels of buildings (and thus different operational requirements), but requiring the performance to be verified at different levels of seismic intensity (as is currently done in NZS 1170.5 by defining different SLS2 return periods for different building importance levels).

\section{Ductility Factor}

The ductility factor $\left(C_{p h}, C_{p}\right.$ or $\left.R\right)$ permits a reduction in the design force if the seismic resisting system is capable of sustaining inelastic deformations without a considerable strength loss. These factors could also account for over-strength in the 
component design. Multiple studies in the past have addressed possible reductions in the design force for structural systems, having different hysteretic characteristics and dynamic properties, and for different types of ground motions. The same concept is now being extended to NSEs utilizing recorded building floor motions.

Kazantzi et al. [55] evaluated strength reduction factors for NSEs idealized as single-degree-of-freedom systems (SDOFs) with a bilinear hysteretic response. The SDOF systems were subjected to recorded floor motions of buildings in California, USA. The study found that possible reductions in the design force are strongly period dependent, and in particular on the proximity of component and building modal periods. Furthermore, the study reported that considerable reductions in the design force can be achieved even for low levels of ductility, for example, 1.5 or 2.0. For components with a damping ratio of $2.0 \%$, that are in resonance with one of the building modal periods, mean reduction values of 3.5, 6.0 and 11 were observed for component ductility values of 1.5, 2.0 and 2.5-3.0 (Figure 10).

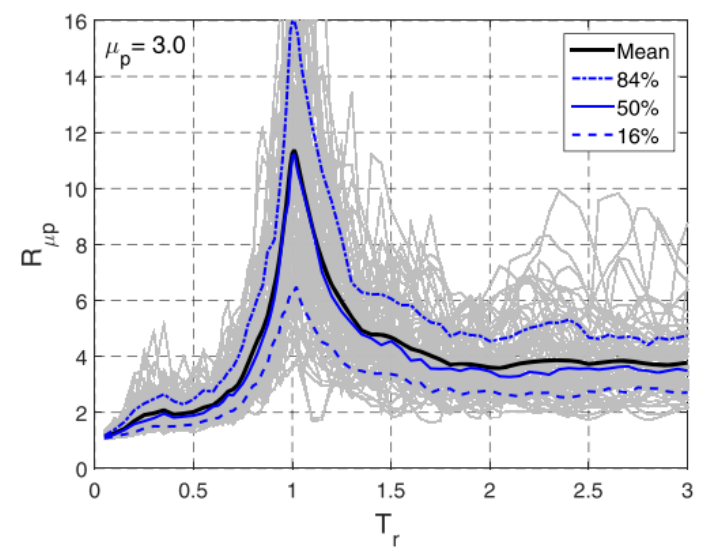

Figure 10: Strength reduction factors $\left(R_{\mu p}\right)$ identified for single degree of freedom systems with bilinear hysteretic behavior and subjected to recorded floor acceleration response histories, for a ductility level $\left(\mu_{p}\right)$ of 3.0 and a damping ratio of $2.0 \%$ [55].

Even after a systematic evaluation of possible reduction factors, a proper evaluation of the ductility capacity of different nonstructural attachments or seismic resisting elements is essential. Acceleration-sensitive NSEs are attached to the supporting floors either directly through floor anchors (e.g., mechanical and electrical equipment) or restrained by sway braces (e.g., ceiling and piping systems). For anchored systems, the inelastic deformation capacity of anchors or their attachments to the component needs to be evaluated. For instance, according to EPRI [56], expansion anchors have ultimate displacement capacities in the range of approximately 0.1 to $0.5 \mathrm{inch}$ ( 2.5 to $12.5 \mathrm{~mm}$ ). In contrast, cast-in-place anchor bolts fail at larger displacement demands.

In the case of perimeter-fixed suspended ceilings, the grids provide the seismic resistance for the whole system as well as the gravity support for the panels. Pourali [44] reported tests on main and cross tee connections typical of perimeter-fixed ceilings. It was shown that such connections do not exhibit any ductility, unless some special provisions are made, as illustrated by the force-deformation response of a cross tee-main tee (CTMT) connection with and without seismic clips in Figure 11. Some bracing systems for braced suspended ceilings used in practice are recommended by the manufacturer to be designed for a ductility factor of 1.0.

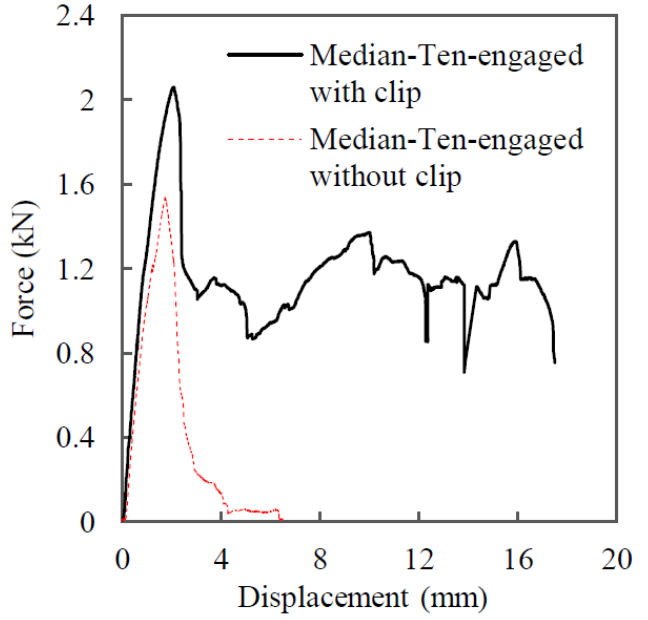

Figure 11: Force-deformation response of a ceiling grid cross tee-main tee connection under tensile loading with and without seismic clips. The brittle response of the connection without the seismic clip is evident from the sudden strength drop. [44].

In other suspended NSEs, such as piping and cable tray systems, the seismic resisting system is formed by sway braces (Figure 12). It is important to mention that bracing systems are tested and approved according to different standards that employ a cyclic loading procedure [57,58]. However, the purpose of approval or qualification test is merely to assign a load rating and no information is given on the post-yield deformation capacity of the components (though the testing procedures do include subjecting the braces to multiple cycles of loading), nor on the likely failure mechanism.

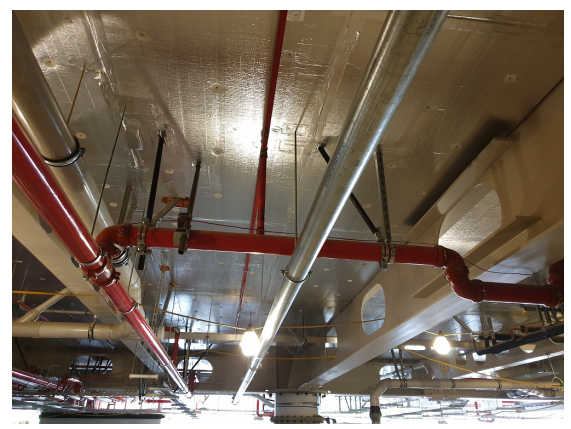

(a) Suspended pipes bracing

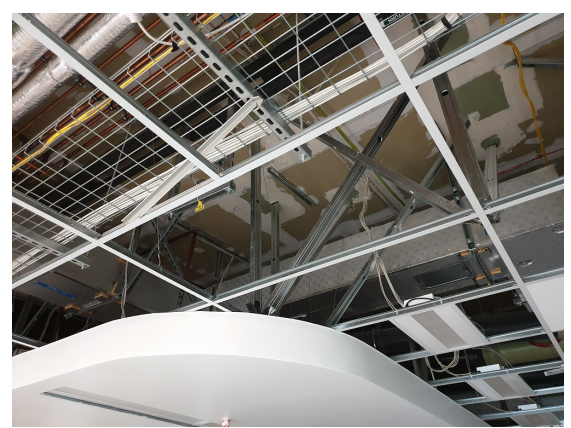

(b) Suspended ceiling bracing

Figure 12: Bracing of suspended NSEs in a hospital building under construction.

Filiatrault et al. [59] reported ductility capacities of 2.5 and 1.5 for lateral and longitudinal trapeze bracing systems under cyclic 
loading. Perrone et al. [60] tested different trapeze systems for piping under monotonic and cyclic loading. All the specimens exhibited ductile behavior with resulting ductility capacities ranging from 1.5 to 5.1. The displacements corresponding to the life-safety performance objective equated to ductility capacities ranging from 1.9 to 4.0 .

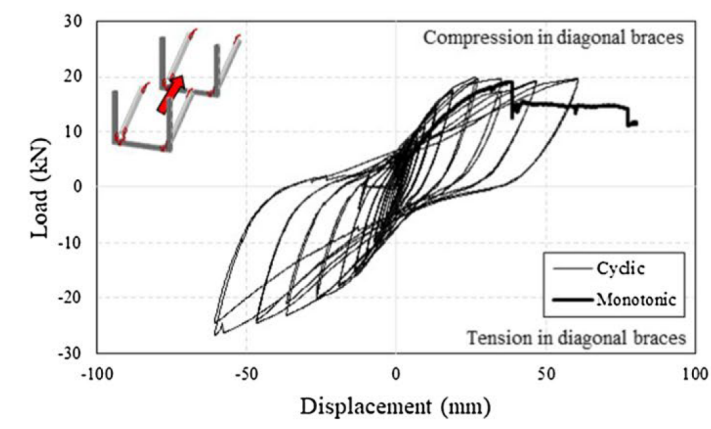

\section{Figure 13: Hysteretic behavior of a trapeze bracing system tested by Perrone et al. [60].}

The NZS 1170.5 does not provide allowable ductility values (to calculate the part horizontal response factor, $C_{p h}$, which is the equivalent of the ductility factor) for braces of distributed systems, such as suspended pipes and cable trays. However, ductility values up to 2.0 are provided for pipes. The NZS 4219 provides performance factors (equivalent to ductility factor) for braces equal to $1.17(1 / 0.85)$, as well as different piping connections up to $4.0(1 / 0.25)$. In relation to suspended ceilings, ductility values up to 2.0 are allowed in NZS 1170.5. Arguably, any consideration of design force reduction by relying on ductility should result in damage to the seismic force resisting elements (e.g., the braces) and not the system itself (e.g., the piping). Given the enormous variability of seismic resisting systems available for NSEs, an engineering approach should be used to establish suitable ductility factors. This could either be done by experimental testing or rational mechanics-based estimations.

Most importantly, it is essential to ensure that any reduction in the design force that relies on ductility should not affect the performance of the system that is required of it. This appears especially important for essential components and systems, where the ductility factor should not offset the enhanced reliability of the design resulting from the application of a risk factor. In other words, it should be checked that by relying on ductility, the target probability of failure is still achievable.

\section{SUMMARY OF KEY OBSERVATIONS: CURRENT NZ PRACTICE ON DESIGN OF ACCELERATION-SENSITIVE NON-STRUCTURAL ELEMENTS}

A scrutiny of the two primary standards for the seismic design of NSEs in New Zealand, NZS 1170.5 and NZS 4219 (non-specific design), with a focus on acceleration-sensitive NSEs has led to the following key observations:

i. The design force equations in NZS 1170.5 and NZS 4219 are similar, except that NZS 4219 provides a relatively simplified design equation without explicitly including the component amplification factor, which appears to be accommodated in the coefficient of 2.70. The design force equations only account for the component non-linearity in estimating the component acceleration demands and not the supporting structure non-linearity. Further, both stan- dards do not include any guidance on how to determine the deformation demands on acceleration-sensitive NSEs.

ii. In both standards, the magnitude of the design force for an NSE is dependent on the importance level of the building. This implies that the same component is required to be designed for different levels of design force (thus different performance) in buildings of different importance levels for the same design limit state. This is because for the same design limit state, buildings of different importance levels are required to be designed for different return period events. Differences in the risk factor for the same building and component categories are observed between NZS 1170.5 and NZS 4219.

iii. A comparison of the component design forces for an IL2 and an IL4 building using the two standards reveals that NZS 4219 leads to comparatively higher design forces than NZS 1170.5. This was intended by the authors of NZS 4219 and is due to the relatively simplified design coefficient in NZS 4219. This comparison was made by assuming the component period was smaller than $0.75 \mathrm{~s}$, in which case the spectral shape coefficient in NZS 1170.5 was 2.0. For component periods larger than $0.75 \mathrm{~s}$, NZS 1170.5 will lead to even smaller design forces than NZS 4219, given that the spectral shape coefficient follows a linear reduction beyond the period of vibration of $0.75 \mathrm{~s}$.

iv. When compared with the design provisions in overseas standards (ASCE 7-16 \& EC-8), it was found that the equations used in the NZ standards to calculate the design force for acceleration-sensitive NSEs are conceptually similar to the corresponding formulations used in overseas standards. Nevertheless, a comparison between the calculated design coefficients according to the different standards reveals quantitative differences. For example, the design seismic force for a piping system on the roof of a building was calculated using the different standards. Despite the same ground acceleration, the resulting design forces varied by up to a factor of 3.60. It is important to note that the relative difference in the design force is not the same as the design coefficient due to the different values of performance factors used in the standards.

v. There is a considerable body of literature demonstrating that the floor and component acceleration demands are a function of the dynamic characteristics of the supporting structure and the component. The empirical floor and component amplification factors used in the NZ design standards do not result in a reliable estimation of the component demand given that these factors are assigned fixed values. This can lead to considerable underestimation and overestimation of the demand.

vi. Researchers and practitioners universally accept that despite being subjected to the same ground excitation, different building structural systems will have different dynamic responses, thereby inducing varying acceleration demands on NSEs installed in buildings with different structural systems. However, the NZ design standards require a given NSE to be designed for the same force regardless of whether it is in a strong/weak, stiff/flexible, tall/short, highly ductile/nominally ductile building, as long as the buildings are in the same seismic zone and used for the same purpose (same importance level). This is considered to be a fundamental shortcoming. Other international standards also contain this shortcoming. The latest ATC approach accounts for building non-linearity in quantifying the NSE design force. 
vii. The inconsistent demand estimation procedures (hence inevitably different estimations of strength by NZS 1170.5 and NZS 4219), the lack of reliable displacement design criteria consistent with performance objectives, and the use of proprietary products without giving due consideration to the anticipated seismic demand and component capacity, are considered to be major impediments to achieving a design approach that can be relied upon to attain the intended performance objectives for NSEs.

\section{PROPOSED WAY FORWARD}

\section{Improved Design Procedure and Research Needs}

A comprehensive seismic design procedure for accelerationsensitive NSEs that is aimed at achieving the target performance objectives, specified in the design standards, should have the following three major requirements:

1. Defining suitable design criteria, including acceleration or force limit states and associated deformation limits, consistent with performance objectives;

2. Estimating the component or system demand;

3. Designing and proportioning of force resisting elements based on the anticipated demands and capacity design principles.

Research needs vary for each area above as briefly described below.

\section{Research Needs}

\section{Defining Design Criteria}

i. Acceleration or force levels for different limit states $\rightarrow$ not much work needed as the performance objectives for different components and systems (e.g., life-safety or functionality) and the seismic intensity (or limit states e.g., SLS1, SLS2, ULS) at which the performance is required are defined in Table 8.1 of NZS 1170.5 [22].

ii. Deformation limits for components and systems at different damage states $\rightarrow$ need experimental and/or numerical evaluation.

iii. Risk factors $\rightarrow$ probabilistic evaluation of performance needed to check attainment of acceptable risk levels.

\section{Estimation of Seismic Demand}

i. A demand estimation procedure is required that is simple and yet robust. It should account for the building and the component dynamic characteristics, as well as other possible factors, such as building and component non-linearity.

ii. Component and system vibration periods $\rightarrow$ need guidance for analytical formulations or evaluation by experiments.

iii. Component and system damping ratios $\rightarrow$ need experimental research, either in-situ or lab testing.

iv. Ductility capacities of different non-structural support systems, such as anchorage and bracing types $\rightarrow$ need experimental investigations or a mechanics-based approach.

v. There is a need for guidance to numerically model nonstructural components and systems to estimate the design forces and displacements.

\section{Design \& Proportioning}

i. There is a need for guidance not only on the strength but also the deformation capacity of acceleration-sensitive NSEs.

ii. Capacity design $\rightarrow$ needs to be implemented in the design of NSEs, including proprietary bracing assemblies.

\section{New Seismic Rating Framework}

Sullivan et al. [61] recently proposed a seismic rating framework, which is herein discussed with regards to acceleration-sensitive NSEs. The framework proposes that NSEs should be rated based on their acceleration and drift capacities. This implies that the specification and detailing of NSEs for a particular building could be based on the anticipated drift and acceleration demands in that building. Further, the approach takes into consideration the required performance at different seismic intensity levels by specifying the required capacities in terms of serviceability and ultimate limit state accelerations, which correspond to nodamage and life-safety, respectively. Hence, the performance expectations can be clearly communicated for a component or system right from the beginning of the design process.

The rating framework includes a classification system in which acceleration-sensitive NSEs are divided into five classes from A1 to A5 (Table 7). Each class identifies a certain performance requirement in terms of SLS (no-damage) and ULS (life-safety) peak floor acceleration (PFA) capacities and clearance requirements. For instance, if a building structure has SLS and ULS roof acceleration demands of $0.3 \mathrm{~g}$ and $0.8 \mathrm{~g}$, equipment from the NSE class A2 will be required for installation. Note that the specified acceleration and clearance values were proposed as place holders based on technical reasoning and need to be refined based on further investigations.

In order to assess the adequacy of an NSE for a particular class, the floor acceleration demands given in Table 7, need to be converted into corresponding component acceleration demands. This is proposed to be done using the standardized floor response spectrum shown in Figure 14. In principle, the dynamic amplification factor (DAF) should be calculated using a formulation that accounts for the building and component dynamic characteristics (e.g., Haymes et al. [37]). However, since the classification of an NSE should be applicable to a wide range of buildings, the proposal by Sullivan et al. [61] indicates a standard floor response spectrum with a wide amplification plateau. The component or system capacity can either be determined through testing or structural mechanics or using alternative means, such as historical data. The estimation of capacity should consider the variability in response to different possible floor excitation.

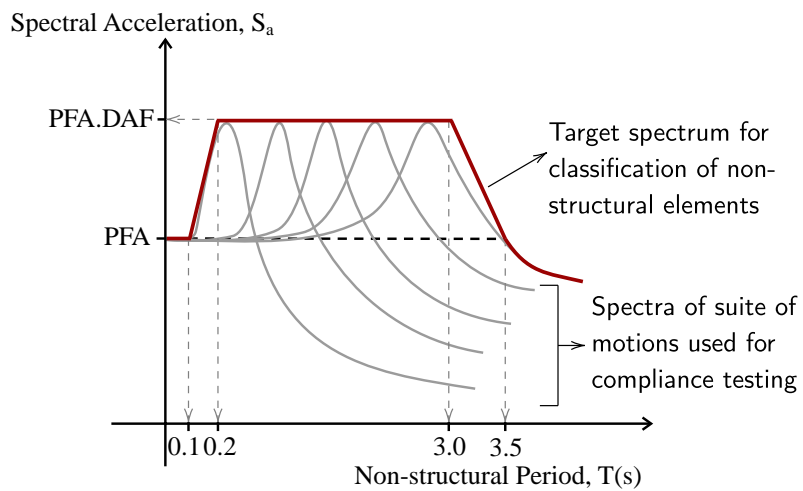

Figure 14: Standardized floor response spectrum proposed for the classification of acceleration-sensitive NSEs. 
01: Define Design Criteria Consistent with Performance Objectives

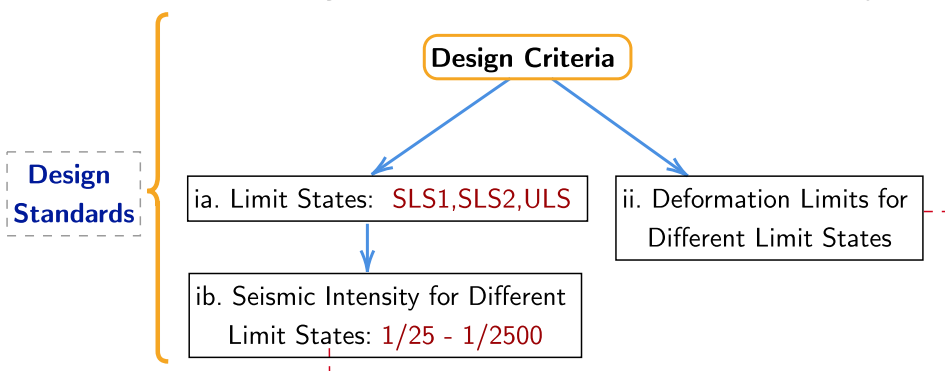

02: Identify Required Component or System Capacity Class

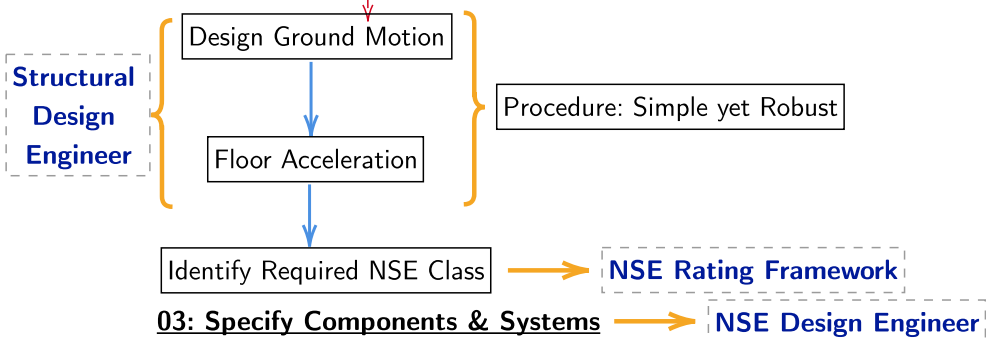

3a: Specification Via Pre-Qualified Components

Selection of component from the available proprietary options that has the required NSE class SLS and ULS capacities. 3b: Specification Via Engineering Design

Force Based Design

1. Obtain $\mathrm{T}_{\mathrm{NS}} \& \zeta_{\mathrm{NS}}$ and Compute Component or System Acceleration.

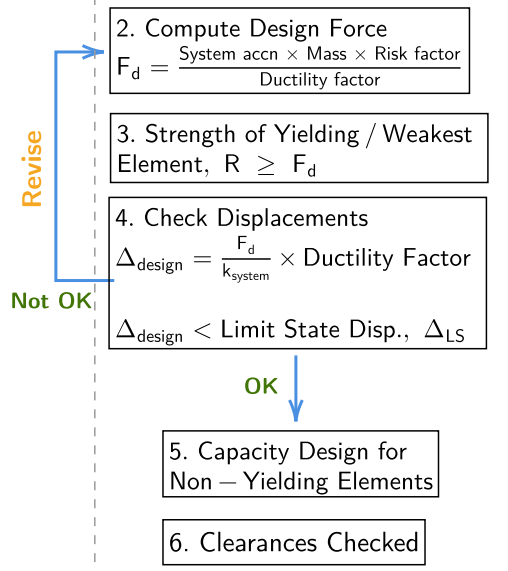

Displacement Based Design

1. Quantify Limit State Displacement Capacity, $\Delta_{\mathrm{LS}}$

2. Compute Spectrum Scaling Factor $(\eta)$ for System Ductility / Damping

3. Strength of Yielding / Weakest Element, $\mathrm{R} \geq \mathrm{F}_{\mathrm{d}}=\mathrm{k}_{\mathrm{e}} \Delta_{\mathrm{LS}}$

4. Capacity Design for Non - Yielding Elements

5. Clearances Checked

Notations:

$\mathrm{T}_{\mathrm{NS}}=$ Non - structural period

$\zeta_{\text {NS }}=$ Non - structural damping

$\mathrm{k}_{\mathrm{system}}=$ System stiffness

$k_{e}=$ Effective system stiffness

Figure 15: Framework of an improved design procedure for acceleration-sensitive NSEs.

The proposed classification system is considered to have practical advantages. First, the approach will help improve the communication of seismic capacity requirements for NSEs. The classification system will clearly identify the NSEs required, and with time, it is expected that the costs and time required to achieve different capacity classes will be well understood. The installation of NSEs in a building will thus be performance-based. Secondly, since the majority of a building cost is constituted by NSEs [16], the framework allows non-structural design choices to feed into the selection of the structural system, such that the cost of the NSEs and thereby the building cost can be minimized. For example, if the floor acceleration demands of a certain structural system require costly NSEs to meet the performance objectives, the structural system can be changed (say from structural walls to moment frames) to reduce the peak floor acceleration demands and hence the cost of NSEs, without compromising on the performance objectives. Lastly, this framework might make the inspection process easier for the same NSEs by simply requiring a conformity check between the example elements for the required NSE class and the as-built element.

\section{Link between the Design Procedure and the Rating Framework}

A design procedure that links with the rating framework is illustrated by a flowchart in Figure 15. The roles of the design standards, the structural and non-structural design engineers (or suppliers) and the new seismic rating framework are shown in the flowchart. The proposed rating framework serves to communicate the capacity requirements for NSEs between the structural and non-structural design engineers (or suppliers). This is explained in the following three steps:

i. The structural design engineer will compute the expected floor accelerations using a robust procedure for the SLS (no-damage) and ULS (life-safety) performance levels.

ii. The floor accelerations for the SLS and ULS performance levels will identify the required NSE class in the rating framework (Table 7), for the selection of components and 
Table 7: Tentative PFA values and clearance requirements proposed for the seismic classification of acceleration-sensitive NSEs in NZ (modified from Sullivan et al. [61]).

\begin{tabular}{ccccc}
\hline & \multicolumn{2}{c}{$\begin{array}{c}\text { Peak Floor } \\
\text { Acceleration Capacity }(\mathbf{g})\end{array}$} & $\begin{array}{c}\text { Installation Clearance } \\
\text { Requirements (mm) }\end{array}$ \\
\cline { 2 - 5 } NSE Class & $\begin{array}{c}\text { SLS } \\
\text { (No-damage) }\end{array}$ & $\begin{array}{c}\text { ULS } \\
\text { (Life-safety) }\end{array}$ & $\begin{array}{c}\text { Short Period } \\
(\mathbf{T}<\mathbf{0 . 1 s})\end{array}$ & $\begin{array}{c}\text { Medium Period } \\
(\mathbf{T}=\mathbf{1 . 0 s})\end{array}$ \\
\hline A1 & 0.10 & 0.25 & 5 & 50 \\
A2 & 0.25 & 0.60 & 10 & 100 \\
A3 & 0.50 & 1.0 & 15 & 150 \\
A4 & 0.75 & 1.50 & 20 & 200 \\
A5 & 1.0 & 2.0 & 30 & 300 \\
\hline
\end{tabular}

seismic force resisting elements (bracing type, spacing and anchorage) with the required capacity.

iii. The designer or supplier of the NSEs will have to ensure that the NSEs selected and proportioned for installation have the required NSE class capacity.

Depending on whether the NSE is a single component, such as a piece of equipment, or a distributed system like a cable tray system, the designer of the NSE will have to adopt different approaches (qualification vs. engineering design) to ensure that the selected component or the system design has the required floor acceleration capacity for a performance level as per the NSE class. This process is explained below for both types of acceleration-sensitive NSEs.

\section{Components}

The acceleration capacity of an individual component, such as a piece of equipment, at different performance levels, could be evaluated through dynamic testing (or historical evidence, if available). This should provide the acceleration demand at which the component itself remains undamaged or functional. Such testing should also lead to the identification of the acceleration demand at which there is any damage to its connections with the supporting structure. Such limit state capacities of different proprietary components would lead to their classification in one of the five NSE classes in the rating framework. This will result in a simple selection of components based on the required NSE class capacity (communicated by the structural design engineer for a building) for a future project (see Figure 15). However, the implementation of this approach requires a standardized testing protocol for a consistent estimation of component limit state capacities in terms of floor accelerations. If the capacity of a component is to be computed based on engineering design, the approach shown in part $3 \mathrm{~b}$ of the design flowchart illustrated in Figure 15 could be followed.

\section{Distributed Systems}

For distributed systems, such as piping and cable trays, testing may not be a practical option given the scale of these systems, and that such systems not only vary from building to building, but can also vary from floor to floor within the same building. The periods of vibration of these systems will vary due to different mass (e.g., smaller vs. larger pipe) and stiffness properties (e.g., pipe size and brace spacing) from one application to another. Hence, the determination of the demand and capacity of these systems is not straightforward and will require an engineering approach as illustrated in Figure 16. The performance levels for these systems can be related to the performance of the seismic sway bracing and the system itself (such as pipe leakage). To check if a proprietary brace assembly with a certain capacity rating, corresponding to a limit state, qualifies for an NSE class, the force capacity needs to be expressed in terms of the corresponding peak floor acceleration. This can be calculated using Equation 18.

$$
P F A=\frac{R_{b} \times \sin \theta \times R_{\mu}}{D A F \times m_{t} \times R_{p}}
$$

where, $P F A=$ peak floor acceleration corresponding to $R_{b}, R_{b}=$ brace force capacity corresponding to a limit state, $\theta=$ angle of the brace with the vertical, $R_{\mu}=$ ductility factor dependent on the system ductility capacity $(\geq 1.0), D A F=$ dynamic amplification factor as given by Figure 14, $m_{t}=$ tributary seismic mass for the brace, $R_{p}=$ risk factor for the system $(\geq 1.0)$.

The brace force capacity, $R_{b}$, corresponding to yield (SLS - nodamage) and ultimate strength (ULS - life-safety) should be provided by the manufacturer based on standardized approval testing. The brace inclination, $\theta$, is dependent on practical constraints during installations. For a given system, the tributary seismic mass, $m_{t}$, is dependent on the brace spacing and can easily be determined in line with the standard guidelines (e.g., Standards New Zealand [24]).

To follow the engineering design approach illustrated in Figure 16, the system acceleration demand needs to be computed. For the estimation of system acceleration demand (PFA.DAF), it could be conservatively assumed that the system is in resonance with a building modal period and the dynamic amplification factor can be calculated using a reliable method (e.g., Haymes et al. [37]). Otherwise, the period of vibration of the system needs to be determined to use an appropriate dynamic amplification factor. The damping ratio of the system can be obtained from guidance documents or standard literature.

If the ductility factor is to be used to accommodate large acceleration demands, the deformation (ductility) capacity of a brace assembly should be provided by the manufacturer with proper definitions of yield and ultimate displacement capacities. Since for brace assemblies, yielding is proposed as a no-damage criterion based on Perrone et al. [60], no reduction in the required capacity for SLS should be allowed. For the ULS, reduction in the required capacity (and thus the required PFA) could be permitted as long as experimental evidence is provided on the ductility capacity of the brace assembly.

Further, since the brace assemblies are connected to the supporting floor using anchors, and the failure of anchors can compromise the performance of the bracing, it is recommended that the 
1. Obtain $T_{N S} \& \zeta_{N S}$ and compute system acceleration.
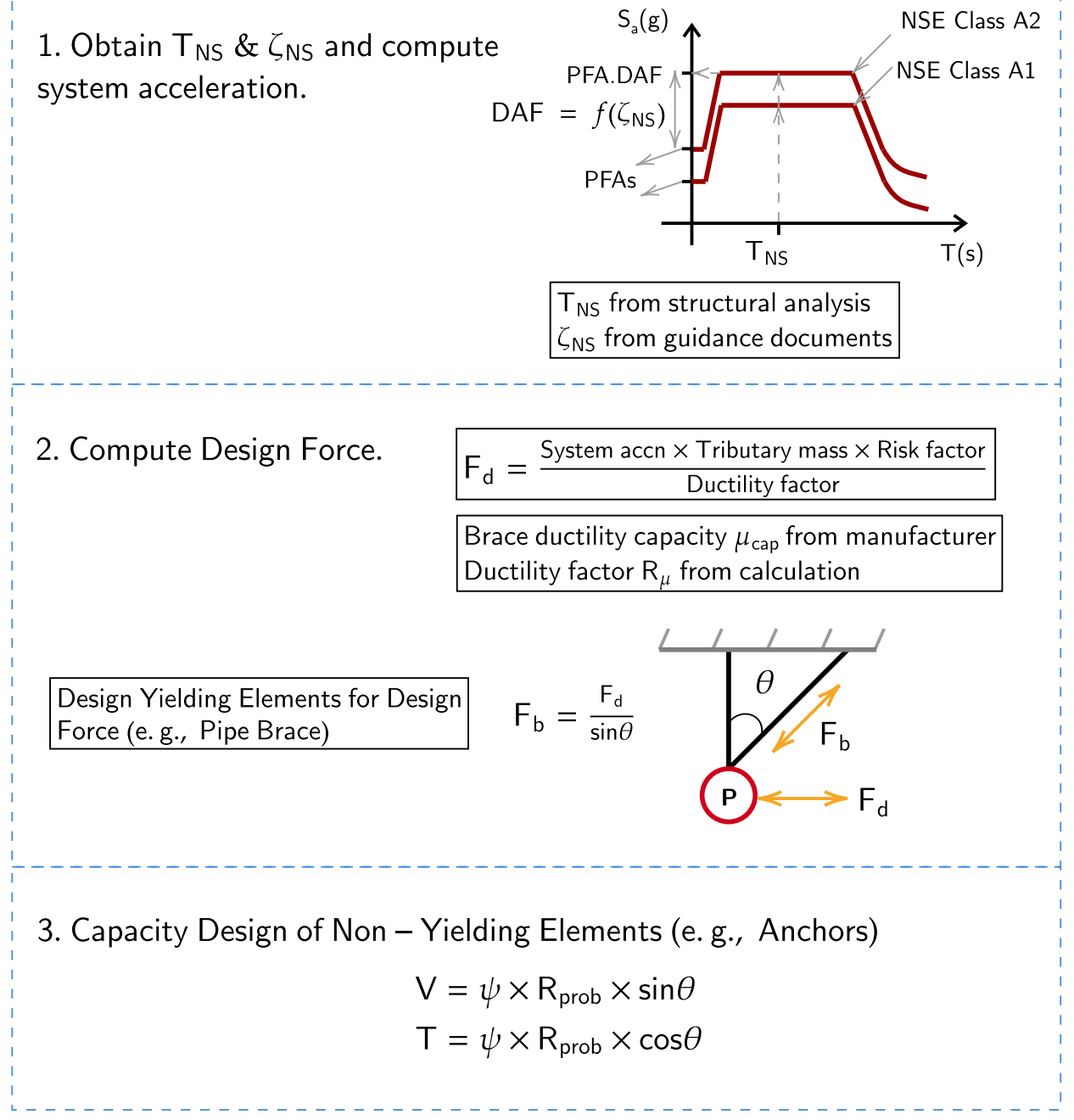

Figure 16: Seismic design of braced distributed systems using the proposed rating framework.

required anchor capacity (tensile \& shear) be increased by an appropriate over-strength factor to ensure that the brace assembly yields first at the ULS loading (the need for this is further elaborated in the next section). The required capacity of an anchor should be determined as follows:

$$
\begin{aligned}
& V=\psi \times R_{\text {prob }} \times \sin \theta \\
& T=\psi \times R_{\text {prob }} \times \cos \theta
\end{aligned}
$$

where, $V=$ required shear capacity of an anchor corresponding to the brace over-strength capacity, $T=$ required tensile capacity of an anchor corresponding to the brace over-strength capacity, $R_{\text {prob }}=$ probable brace capacity corresponding to the ultimate limit state, $\psi=$ over-strength factor, $\theta=$ angle of the brace with the vertical.

As regards the performance levels of distributed systems related to damage to the system itself (such as pipe leakage or failure of a cable tray), the estimated design displacement demands should be compared against the capacity of the system at different limit states to ensure that the desired performance is achieved. This is illustrated in part $3 \mathrm{~b}$ of the design flowchart in Figure 15.

\section{Capacity Design}

Currently, unlike structural systems, the gravity and seismic force resisting elements for NSEs are usually not proportioned and detailed by design engineers. The geometry and material properties of these elements are pre-defined and usually consist of three components: i) brace element, ii) NSE-attachment component and iii) building-attachment component. Together these components form a brace assembly, which is used to restrain different piping systems, suspended ceilings and cable trays. Such brace assemblies are connected to the supporting structure (beam or slab) using anchors (see Figure 17).

The attachment components are tested according to standard approval procedures for assignment of capacity ratings [57,58]. The capacity of brace elements, being of typical geometry (e.g., hollow circular or channel section) and materials, can be manually calculated. This implies that the current design procedure primarily involves comparing the brace design forces with the capacity rating of a chosen system (attachment components) and the design of anchors for the anticipated demands. It is, however, not clear as to what is usually the difference between the calculated design force and the load rating of a chosen system. Based on a review of typical brace assemblies used in NZ, the authors suspect that, in some cases, the difference can be considerable.

The strength of a typical brace element (e.g., hollow circular or channel section) is usually considerably higher than the capacity ratings of typical attachment components. For example, for a $25 \mathrm{NB}$ pipe section, the tensile yield strength is $98.12 \mathrm{kN}$ considering steel yield strength to be $320 \mathrm{MPa}$, whereas a review of typical attachment components revealed comparatively smaller capacities. Further, a review of typical anchors shows that their capacities are also much smaller than the capacity of typical 


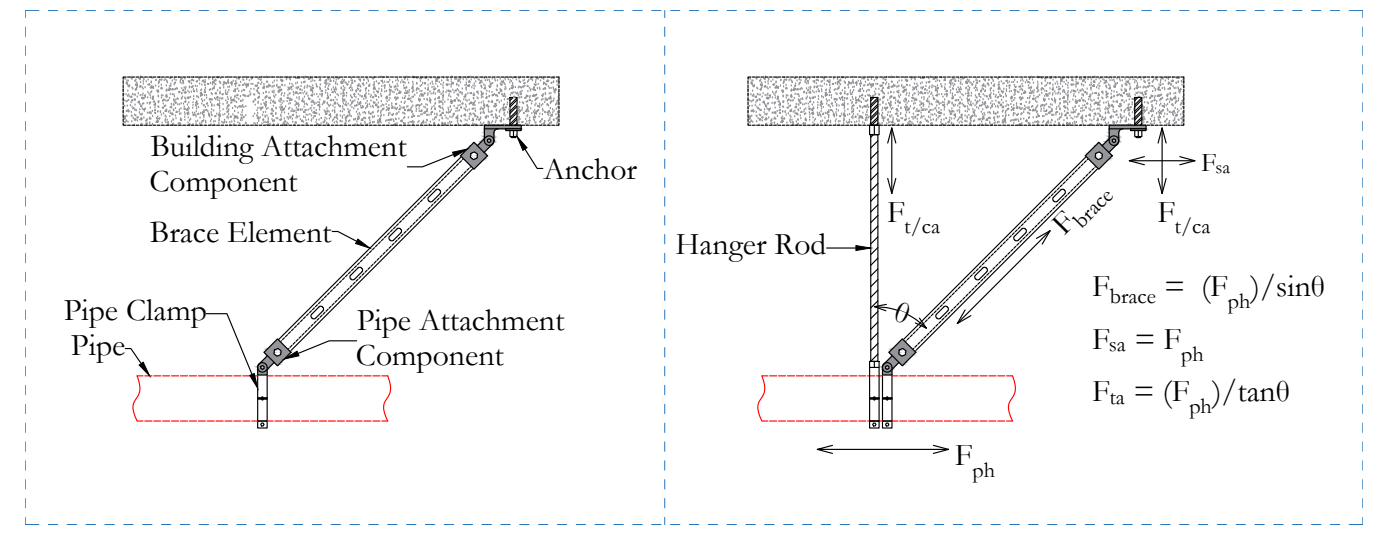

Figure 17: Brace assembly components \& their seismic force demand resulting from horizontal seismic pipe force.

(a)

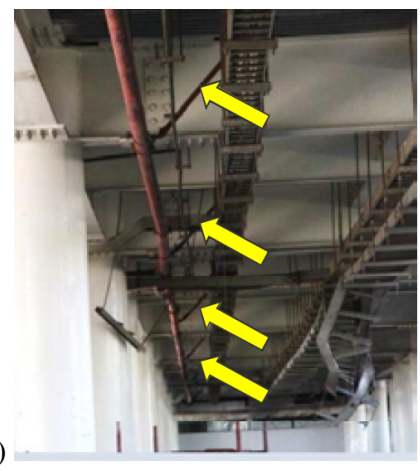

(b)

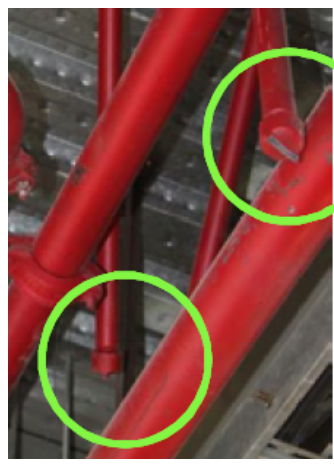

(c)

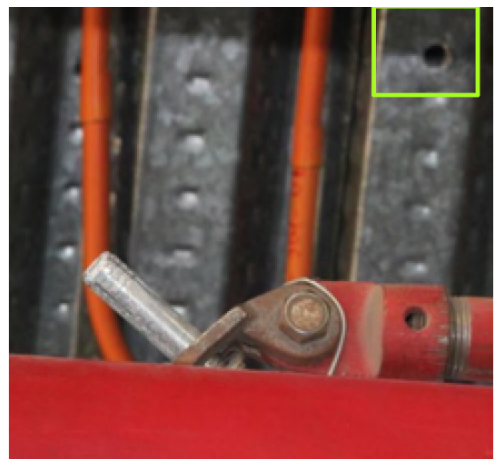

Figure 18: Damage to piping brace assemblies and anchors in 2010 Chile Earthquake: a) sprinkler pipe brace failures; b) close-up of brace failures; c) brace anchor failure [62].

brace elements (especially considering the anchor capacity under simultaneous tension and shear). This discussion leads to the conclusion that in a seismic event, if the demand exceeds the design force, the failure will most likely occur in the anchors, if the difference between the calculated design force and the capacity rating of the attachment component is significant (because the attachment component will not yield at the design force). The authors regard anchor failure as an undesirable failure mode because of its brittle nature. Further, special care needs to be exercised if the design also includes a ductility factor (which will permit higher floor accelerations to be resisted) because the anchor might become a structural fuse if proper capacity design is not carried out.

The solution to this problem is that the design of brace assemblies should be overhauled based on the principles of capacity design, where the brace assembly (with a ductile post-yield response) should always yield upon exceedance of design force rather than the brittle anchor. Otherwise, sufficient protection should be provided against the failure of anchors. With the current brace assemblies, once the bracing system is chosen, the anchors could be designed for the over-strength capacity of the weakest component in the brace assembly, rather than for design forces calculated in accordance with Equation 1 and Equation 4. This is described by Equation 19 and Equation 20, where the required shear and tensile capacities of an anchor are calculated based on the over-strength capacity of the weakest component (yielding) in the brace assembly.

This approach assumes that the higher mode effects on NSEs are not significant. This may not always be the case and if required, allowance for higher mode effects could also be made. The use of a capacity design approach for NSEs has also been recommended by Miranda et al. [63], wherein evidence is also provided on the possible reductions in the design force (by re- lying on ductility) and the displacement response of inelastic NSEs. Consistent with traditional seismic design, the weakest element in the brace assembly should behave in a ductile manner when the design force is exceeded to ensure a sustained load path and reduce sensitivity to variations in demand; otherwise, the brittle failure of a component in the brace assembly will have the same consequences as an anchor failure.

\section{RECOMMENDATIONS}

This section provides recommendations on how to improve the current seismic design practices for acceleration-sensitive nonstructural elements in NZ standards. These recommendations are intended to enable the selection of components and systems, and the design of their seismic force resisting elements, based on the anticipated demand and the component capacity, for a performance level under consideration.

1. Unlike structural systems, which are required to satisfy both SLS and ULS performance levels, most non-structural elements have a unique performance objective. Non-structural elements that are not critical for the continuous operation of important facilities, but can pose life-safety threats, should be designed for the same level of risk irrespective of the building use.

2. A practical yet accurate demand estimation procedure that accounts for the building and component dynamic characteristics should be adopted. This paper has provided an overview of a recently proposed and validated procedure that can lead to reliable estimates of component demand. To use such procedures, experimental and/or numerical investigations are needed to evaluate periods of vibration and damping of non-structural elements. 
3. The acceleration demand on components can be reduced by relying on the non-linear deformation capacity of their seismic force resisting elements. Given the wide range of force resisting elements available for NSEs, the allowable ductility factors in the design standards should be based on experimental evidence. The ductility capacity of such elements can be taken from their qualification tests, which employ a cyclic loading protocol. The proportioning of ductile seismic force resisting assemblies should follow capacity design principles to ensure that damage is concentrated in the weakest and ductile element of the assembly.

4. The current design procedure for acceleration-sensitive nonstructural elements requires improvements in order to reliably achieve target performance objectives. In addition to a robust estimation of demand, this necessitates design criteria that include determination of the strength and deformation limits consistent with different damage states, and the design and proportioning of force resisting elements based on the anticipated demand and capacity design principles. The framework of an improved design procedure is provided and the associated research needs are identified for the implementation of such a procedure.

5. The presented seismic rating framework for evaluating the required capacity of non-structural elements is recommended for application in practice, given its performancebased classification of components and the ease with which capacity expectations can be communicated. By application to acceleration-sensitive individual components and distributed systems, it is illustrated how the recommended design procedure and the proposed rating framework can be used in conjunction to design NSEs for different performance levels based on the anticipated demand.

\section{ACKNOWLEDGMENTS}

The authors acknowledge the constructive feedback provided by the reviewers. This work was conducted under the Building Innovation Partnership (BIP) program co-funded by MBIE and Industry.

\section{REFERENCES}

1 Dhakal RP (2010). "Damage to non-structural components and contents in the 2010 Darfield earthquake". Bulletin of the New Zealand Society for Earthquake Engineering, 43(4): 404-411. https://doi.org/10.5459/bnzsee.43.4.404-411

2 Dhakal RP, MacRae GA and Hogg K (2011). "Performance of ceilings in the February 2011 Christchurch earthquake". Bulletin of the New Zealand Society for Earthquake Engineering, 44(4): 377-387. https://doi.org/10.5459/bnzsee.44. 4.377-387

3 Baird A and Ferner H (2017). "Damage to non-structural elements in the 2016 Kaikōura earthquake". Bulletin of the New Zealand Society for Earthquake Engineering, 50(2): 187-193. https://doi.org/10.5459/bnzsee.50.2.187-193

4 Bradley BA, Dhakal RP, Cubrinovski M and Macrae GA (2009). "Seismic loss estimation for efficient decision making". Bulletin of the New Zealand Society for Earthquake Engineering, 42(2): 96-110. https://doi.org/10.5459/bnzsee. 42.2.96- 110

5 MBIE (2017). "Economic Benefits of Code Com pliant Non-structural Elements in New Buildings". Ministry of Business, Innovation and Employment. https://www.mbie.govt.nz/assets/decf694d37/economicsrelating-to-the-seismic-performance-of-non-structuralelements-v2.pdf
6 MacRae GA, Pampanin S, Dhakal RP and Palermo A (2012). "Review of Design and Installation Practices of Nonstructural Elements". Project 42 Report for the Engineering Advisory Group, Department of Building and Housing, 82 pp.

7 Baird A (2014). "Seismic Performance of Precast Concrete Cladding Systems". PhD Dissertation, University of Canterbury, Christchurch, New Zealand. https://ir.canterbury.ac.nz/ handle/10092/9997

8 Pourali AB, Dhakal RP and MacRae GA (2014). "Seismic performance of suspended ceilings: Critical review of current design practice". Annual Conference of the New Zealand Society for Earthquake Engineering, Auckland, New Zaland.

9 Tasligedik AS, Pampanin S and Palermo A (2015). "Low damage seismic solutions for non-structural drywall partitions". Bulletin of Earthquake Engineering. https://doi.org/ 10.1007/s10518-014-9654-5

10 Dhakal RP, Pourali AB and Saha S (2016). "Simplified seismic loss functions for suspended ceilings and drywall partitions". Bulletin of the New Zealand Society for Earthquake Engineering, 49(1): 64-78. https://doi.org/10.5459/bnzsee. 49.1.64-78

11 Dhakal RP, Pourali AB, Tasligedik AS, Yeow T, Baird A, Pampanin S and Palermo A (2016). "Seismic performance of non-structural components and contents in buildings: An overview of NZ research". Earthquake Engineering and Engineering Vibration, 15(1): 1-17. https://doi.org/10.1007/ s11803-016-0301-9

12 Yeow TZ, MacRae GA, Dhakal RP and Bradley BA (2018). "Validating the sliding mechanics of office-type furniture using shake-table experiments". Bulletin of the New Zealand Society for Earthquake Engineering, 51(1): 1-11. https://doi. org/10.5459/bnzsee.51.1.1-11

13 Dhakal RP, Rashid M, Bhatta J, Sullivan TJ, MacRae GA, Clifton GC, Jia LJ and Xiang P (2019). "Shake table tests of multiple non-structural elements in a low - damage structural steel building". Proceedings of the 4th International Workshop on the Seismic Performance of Non-Structural Elements (SPONSE), Pavia, Italy.

14 Khakurel S, Yeow TZ, Chen F, Wang Z, Saha SK and Dhakal RP (2019). "Development of cladding contribution functions for seismic loss estimation". Bulletin of the New Zealand Society for Earthquake Engineering, 52(1): 23-43. https: //doi.org/10.5459/bnzsee.52.1.23-43

15 Arifin FA, Francesco GD, Sullivan TJ and Dhakal RP (2020). "Developing guidelines for the seismic assessment of glazing systems". Annual Conference of NZ Society for Earthquake Engineering, Wellington, New Zealand.

16 Khakurel S, Dhakal RP, Yeow TZ and Saha SK (2020). "Performance group weighting factors for rapid seismic loss estimation of buildings of different usage". Earthquake Spectra, 36(3): 1141-1165. https://doi.org/10.1177/ 8755293019901311

17 Mulligan J, Sullivan TJ and Dhakal RP (2020). "Experimental seismic performance of partly-sliding partition walls". Journal of Earthquake Engineering. https://doi.org/10.1080/ 13632469.2020.1733139

18 Bhatta J, Dhakal RP and Sullivan TJ (2020). "Low-damage rocking precast concrete cladding panels: Design approach and experimental validation". Journal of earthquake engineering. https://doi.org/10.1080/13632469.2020.1830201

19 Pourali AB, Tata K, Baird A and Kam WY (2020). "Seismic assessment and restraint of non-structural elements practical solutions and implementation challenges". Annual 
Conference of the New Zealand Society for Earthquake Engineering, Wellington, New Zaland.

20 Stanway J, Sullivan TJ and Dhakal RP (2018). "Towards a new delivery approach to improve the performance of non-structural elements in New Zealand". 17th U.S.-JapanNew Zealand Workshop on the Improvement of Structural Engineering and Resilience, Queenstown, New Zealand.

21 Filiatrault A, Perrone D, Merino RJ and Calvi GM (2018). "Performance-based seismic design of nonstructural building elements". Journal of Earthquake Engineering. https://doi. org/10.1080/13632469.2018.1512910

22 Standards New Zealand (2004). "NZS1170.5: Structural Design Actions. Part 5: Earthquake Actions-New Zealand (Incorporating Amendment No. 1)". Standards New Zealand, Wellington, NZ, $86 \mathrm{pp}$

23 Standards New Zealand (2009). "NZS 4219 Seismic Performance of Engineering Systems in Buildings". Standards New Zealand, Wellington, NZ, $111 \mathrm{pp}$.

24 Standards New Zealand (2020). "NZS 4541 Automatic Fire Sprinkler Systems". Standards New Zealand, Wellington, NZ, $440 \mathrm{pp}$.

25 Standards New Zealand (2020). "NZS 2785 Suspended Ceilings - Design and Installation". Standards New Zealand, Wellington, NZ, $43 \mathrm{pp}$.

26 ASCE/SEI 7-16 (2016). "Minimum Design Loads for Buildings and Other Structures, American Society of Civil Engineers". American Society of Civil Engineers, Reston, Virginia, $800 \mathrm{pp}$

27 Comite Europeen de Normalization (2004). "Design Provisions for Earthquake Resistant Structures". European Committee for Standardization, Brussels, Belgium, $231 \mathrm{pp}$.

28 NIST (2018). "Recommendations for Improved Seismic Performance of Nonstructural Components, National Institute of Standards and Technology". National Institute of Standards and Technology, 309 pp. https://nvlpubs.nist.gov/nistpubs/ gcr/2018/NIST.GCR.18-917-43.pdf

29 Ferner H, Jury R, King A, Wemyss M and Baird A (2016). "Performance objectives for non-structural elements". Bulletin of the New Zealand Society for Earthquake Engineering, 49(1): 79-85. https://doi.org/10.5459/bnzsee.49.1.79-85

30 NTC 2018 (2018). "Aggiornamento delle Norme Tecniche per le Costruzioni". Supplemento Ordinario n.8 alla Gazzetta ufficiale del 20.02.2018., Rome, Italy, 372 pp.

31 Miranda E and Taghavi S (2009). "A comprehensive study of floor acceleration demands in multi-story buildings". ATC \& SEI 2009 Conference on Improving the Seismic Performance of Existing Building and Other Structures, pp. 616-626.

32 Miranda E and Taghavi S (2005). "Approximate floor acceleration demands in multistory buildings. I: Formulation". Journal of Structural Engineering, 131(2): 203 211. https://ascelibrary.org/doi/abs/10.1061/\%28ASCE\% $290733-9445 \% 282005 \% 29131 \% 3$ A2\% $28203 \% 29$

33 Taghavi S and Miranda E (2005). "Approximate floor acceleration demands in multistory buildings. II: Applications". Journal of Structural Engineering, 131(2): 212220. https://ascelibrary.org/doi/abs/10.1061/\%28ASCE\% $290733-9445 \% 282005 \% 29131 \% 3$ A2\% $28212 \% 29$

34 Vukobratović V and Fajfar P (2016). "A method for the direct estimation of floor acceleration spectra for elastic and inelastic MDOF structures". Earthquake Engineering \& Structural Dynamics: 2495-2511. https://doi.org/10.1002/ eqe. 2779

35 Sullivan TJ, Calvi MP and Nascimbene R (2013). "Towards improved floor spectra estimates for seismic design". Earthquakes and Structures, 4(1): 109-132. http://dx.doi.org/10. 12989/eas.2013.4.1.109

36 Calvi MP and Sullivan TJ (2014). "Estimating floor spectra in multiple degree of freedom systems". Earthquakes and Structures, 7(1): 17-38. https://doi.org/10.12989/eas.2014.7. 1.017

37 Haymes K, Sullivan TJ and Chandramohan R (2020). "A practice oriented method for estimating elastic floor response spectra". Bulletin of the New Zealand Society for Earthquake Engineering, 53(3): 116-136. https://doi.org/10.5459/ bnzsee.53.3.116-136

38 Uma SR, Zhao JX and King AB (2010). "Seismic actions on acceleration sensitive non-structural components in ductile frames". Bulletin of the New Zealand society for Earthquake Engineering, 43(2): 110-125. https://doi.org/10.5459/ bnzsee.43.2.110-125

39 Rodriguez ME, Restrepo JI and Carr AJ (2002). "Earthquakeinduced floor horizontal accelerations in buildings". Earthquake Engineering \& Structural Dynamics, 31(3): 693-718. https://doi.org/10.1002/eqe.149

40 Medina RA, Ragunath S and Kingston KM (2006). "Floor response spectra for light components mounted on regular moment-resisting frame structures". Engineering Structures: 1927-1940. https://doi.org/10.1016/j.engstruct.2006.03.022

41 Ray-Chaudhuri S and Hutchinson TC (2011). "Effect of nonlinearity of frame buildings on peak horizontal floor acceleration". Journal of Earthquake Engineering, 15(1): 124-142. https://doi.org/10.1080/13632461003668046

42 Anajafi H and Medina RA (2018). "Evaluation of ASCE 7 equations for designing acceleration-sensitive nonstructural components using data from instrumented buildings". Earthquake Engineering \& Structural Dynamics, 47(4): 10751094. https://doi.org/10.1002/eqe.3006

43 Fathali S and Lizundia B (2011). "Evaluation of current seismic design equations for nonstructural components in tall buildings using strong motion records". The Structural Design of Tall and Special Buildings: S30-S46. https://doi. org/10.1002/tal.736

44 Pourali AB (2018). "Seismic Performance of Suspended Ceilings". PhD Dissertation, University of Canterbury, Christchurch, New Zealand. https://ir.canterbury.ac.nz/ handle/10092/16188

45 Welch DP and Sullivan TJ (2017). "Illustrating a new possibility for the estimation of floor spectra in nonlinear multidegree of freedom systems". Proceedings of the 16th World Conference on Earthquake Engineering, Santiago, Chile.

46 Retamales R, Mosqueda G, Filiatrault A and Reinhorn A (2008). "New Experimental Capabilities and Loading Protocols for Seismic Qualification and Fragility Assessment of Nonstructural Systems, MCEER-08-0026". Multidisciplinary Center for Earthquake Engineering Research, 350 pp. http: //www.buffalo.edu/mceer/catalog.host.html/content/shared/ www/mceer/publications/MCEER-08-0026.detail.html

47 Chandramohan R, Ma Q, Wotherspoon LM, Bradley BA, Nayyerloo M, Uma SR and Stephens MT (2017). "Response of instrumented buildings under the Kaikoura earthquake". Bulletin of the New Zealand Society for Earthquake Engineering, 50(2): 237-252. https://doi.org/10.5459/bnzsee.50. 2.237-252

48 Kazantzi A, Vamvatsikos D and Miranda E (2018). "Effect of yielding on the seismic demands of nonstructural elements". Proceedings of the 16th European Conference on Earthquake Engineering, Thessaloniki, Greece. 
49 Merino RJ, Perrone D and Filiatrault A (2020). "Consistent floor response spectra for performance-based seismic design of nonstructural elements". Earthquake Engineering \& Structural Dynamics: 261-284. https://doi.org/10.1002/eqe.3236

50 Watkins DA, Chiu L, Hutchinson TC and Hoehler MS (2009). "Survey and Characterization of Floor and Wall Mounted Mechanical and Electrical Equipment in Buildings, Report No. SSRP-2009/11". University of California, San Diego.

51 Archila M, Ventura C, Figueira A and Yan Y (2012). "Modal testing of non-structural components for seismic risk assessment". Conference Proceedings of the Society for Experimental Mechanics Series 26, pp. 239-246.

52 Yang Y (2011). "Nonstructural Component Field Testing Method for the Evaluation of Seismic Demand Incorporating Floor Response Spectrum". Master thesis, The University of British Columbia, Vancouver, Canada. https://open.library.ubc.ca/soa/cIRcle/collections/ ubctheses/24/items/1.0167326

53 Dhakal RP, Macrae GA, Pourali A and Paganotti G (2016). "Seismic fragility of suspended ceiling systems used in NZ based on component tests". Bulletin of the New Zealand Society for Earthquake Engineering, 49(1): 45-63. https: //doi.org/10.5459/bnzsee.49.1.45-63

54 Soroushian S, Zaghi AE, Maragakis EM and Echevarria A (2014). "Seismic fragility study of displacement demand on fire sprinkler piping systems". Journal of Earthquake Engineering, 18(7): 1129-1150. https://doi.org/10.1080/ 13632469.2014.917059

55 Kazantzi A, Miranda E and Vamvatsikos D (2020). "Strength-reduction factors for the design of light nonstructural elements in buildings". Earthquake Engineering \& Structural Dynamics: 1-15. https://doi.org/10.1002/eqe. 3292
56 EPRI (1993). "Analysis of High-frequency Seismic Effects, Electric Power Research Institute, TR-102470". Electric Power Research Institute, California, US, 192 pp.

57 FM GLobal (2013). "Approval Standard for Seismic Sway Braces for Pipe, Tubing and Conduit". FM Approvals, Johnston, Rhode Island, US, $25 \mathrm{pp}$.

58 ASHRAE (2017). "ANSI/ASHRAE Standard 171-2017 Method of Testing for Rating Seismic and Wind Restraints". ASHRAE Standards, Georgia, US, 13 pp.

59 Filiatrault A, Perrone D, Brunesi E, Beiter C and Piccinin $R$ (2018). "Effect of cyclic loading protocols on the experimental seismic performance evaluation of suspended piping restraint installations". International Journal of Pressure Vessels and Piping: 61-71. https://doi.org/10.1016/j.ijpvp.2018. 08.004

60 Perrone D, Filiatrault A, Peloso S, Brunesi E, Beiter C and Piccinin R (2019). "Experimental seismic response evaluation of suspended piping restraint installations". Bulletin of Earthquake Engineering, 17(10): 5655-5677. https: //doi.org/10.1007/s10518-019-00755-5

61 Sullivan TJ, Dhakal RP and Stanway J (2020). "A framework for the seismic rating of non-structural elements in buildings". Proceedings of the 17th World Conference on Earthquake Engineering, Sendai, Japan.

62 Miranda E, Mosqueda G, Retamales R and Peckan G (2012). "Performance of nonstructural components during the 27 February 2010 Chile earthquake". Earthquake Spectra, 28(1_suppl1): 453-471. https://doi.org/10.1193/1.4000032

63 Miranda E, Kazantzi A and Vamvatsikos D (2018). "New approach to the design of acceleration-sensitive non-structural elements in buildings". Proceedings of the 16th European Conference on Earthquake Engineering, Thessaloniki, Greece. 